\title{
LIDAR MEASUREMENTS OF THE VARIABILITY OF STRATOSPHERIC PARTICULATES
}

\author{
Prepared by \\ and RICHARD D. HAKE \\ STANFORD RESEARCH INSTITUTE \\ MENLO PARK, CALIFORNIA 94025
}

July 1973

Supported by

CIAP OFFICE

U.S. DEPARTMENT. OF TRANSPORTATION

WASHINGTON, D.C. 20590

Prepared under Contract NAS2-7261

for

AMES RESEARCH CENTER

NATIONAL AERONAUTICS AND SPACE ADMINISTRATION MOFFETT FIELD, CALIFORNIA 94035

Reproduced by

NATIONAL TECHNICAL

INFORMATION SERVICE

US Department of Commerce

Springtield, VA. 22151

\section{STANFORD RESEARCH INSTITUTE}

Menlo Park, California 94025 - U.S.A.

(NASA-CR-139273) LIDAR MEASUREMENTS OF

THE VARIABILITY OF STRATOSPHERIC

PARTICULATES Semiannual Report (Stanford

Research Inst.) 56 ? HC $\$ 6.00$ CSCI $20 \mathrm{E}$ 


\title{
LIDAR MEASUREMENTS OF THE VARIABILITY OF STRATOSPHERIC PARTICULATES
}

\author{
Prepared by \\ PHILIP B. RUSSELL, WILLIAM VIEZEE, \\ and RICHARD D. HAKE \\ STANFORD RESEARCH INSTITUTE \\ MENLO PARK, CALIFORNIA 94025 \\ Supported by \\ CIAP OFFICE \\ U.S. DEPARTMENT OF TRANSPORTATION \\ WASHINGTON, D.C. 20590
}

Prepared under Contract NAS2-7261

SRI Project 2217

Approved by

R. T. H. COLLIS

RAY LEADABRAND

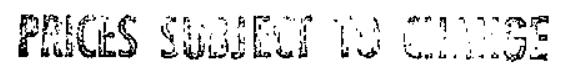

for

AMES RESEARCH CENTER

NATIONAL AERONAUTICS AND SPACE ADMINISTRATION

MOFFETT FIELD, CALIFORNIA 94035

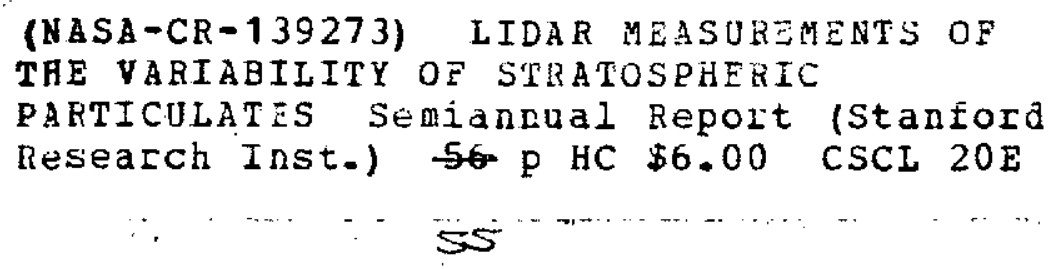

N74-29951

(NASA-CR-139273) LIDAR MEASUREMENTS OF
THE VARIABILITY OF STRATOSPHERTC

PARTICULATES Semiannual Report (Stanfora

Research Inst.) $56 \mathrm{p} \mathrm{HC} \$ 6.00$ CSCI $20 \mathrm{E}$ 


\title{
CONTENTS
}

\begin{abstract}
LIST OF ILLUSTRATIONS . . . . . . . . . . . . . . . . . . iii
LIST OF TABLES . . . . . . . . . . . . . . . . . . . . iv

ACKNOWLEDGEMENT . . . . . . . . . . . . . . . . . . . . $\mathrm{v}$

I INTRODUCTION AND SUMMARY . . . . . . . . . . . . . 1

I I INSTRUMENTATION . . . . . . . . . . . . . 6

III DATA ANALYSIS AND INTERPRETATION . . . . . . . . . . 8

A. Method of Analysis . . . . . . . . . . 8

B. Summary of Data . . . . . . . . . . . . 12

C. Sequential Ruby and Dye Lidar Observations . . . . $\quad 17$

D. Time Variability of Scattering Profiles Within

Nightly Observations . . . . . . . . . . 20

E. Time Variability of scattering Profiles and

Stratospheric Winds: October 1972-June 1973 . . . 22

IV CONCLUSTONS . . . . . . . . . . . . . . . . 26

APPENDIX

IMPORTANCE OF ASSUMED ATMOSPHERIC DENSITY AND

EXTINCTION PROFILES IN THE ANALYSIS OF STRATOSPHERIC

LIDAR DATA . . . . . . . . . . . . . . . . . . A-1
\end{abstract}




\section{ILLUSTRATIONS}

1 Data Sample Showing the Three Principal steps in the Analysis of the Recorded Lidar Backscatter Measurements . . . . . . . . . . . . . . . . . .

2(a) Time Series of Scattering Ratio, $R(Z)$, Versus Height Analyzed from Lidar Backscatter Observations Made at Men1o Park, California . . . . . . . .

2(b) Time Series of Scattering Ratio, $R(z)$, as a Function of Height, Analyzed from Lidar Backscatter Observations Made at Menlo Park, California . . . . . . .

3(a) Time Series of Aerosol Backscattering Coefficient $f_{A}$, Versus Height Computed from Lidar Backscatter Observations Made at Menlo Park, California . . . . . .

3(b) Time Series of Aerosol Backscattering Coefficient $f_{A}$, as a Function of Height, Computed from Lidar Backscatter Observations Made at Menlo Park, California . . . . . . . . . . . . . .

4 Comparison of Lidar Profiles Measured with Ruby Transmitter $(\lambda=0.6943 \mu \mathrm{m})$ and Dye Transmitter $(\lambda=0.5890)$ at Menlo Park, California . . . . . . .

Time Variations of Scattering Ratio Occurring within Nightly Lidar Observations Made at Menlo Park, California . . . . . . . . . . . . . . . . .

6 Time Variability of Layer-Averaged Aerosol Backscattering Coefficient (Heavy Line) and Zonal Wind (Light Line) for Four Altitude Regions . . . . . . .

A-1 Effect on Lidar Scattering Ratio of Assuming Oakland Radiosonde or Standard (Midaltitude Spring-Fa11) Molecular Density Profile . . . . . . . . . . .

A-2 Effect on Lidar Scattering Ratio of Assuming Model [E1 terman, 1968; $\lambda=0.7 \mu$ ] Particulate Extinction or No Particulate Extinction in Computing Molecular Return ...................... 


\section{LIST OF TABLES}

1. Lidar System Parameters . . . . . . . . . . . . . 7 


\section{ACKNOWLEDGMENT}

The stratospheric wind data used in the analysis presented in Section III-E were supplied through courtesy of the Pacific Missile Range, Point Mugu, California. These data are part of the rawinsonde and rocketsonde data routinely collected and disseminated by its Geophysics Division. 


\title{
I INTRODUCTION AND SUMMARY
}

\begin{abstract}
Stanford Research Institute (SRI) is currently making lidar (1aser radar) observations of the variability of particulates in the stratosphere between $10 \mathrm{~km}(33,000 \mathrm{ft})$ and $30 \mathrm{~km}(98,000 \mathrm{ft})$. These observations are part of a lidar program supported by the CIAP office of the Department of Transportation. The goal of CIAP is the assessment of the impact of climatic changes that may result from perturbation of the upper atmosphere by the propulsion effluents of a world high-altitude aircraft fleet as projected to 1990 .
\end{abstract}

The general objective of the SRI laser radar experiment is to provide information on the distribution of particulate material in the natural (unperturbed) stratosphere. The specific objectives are to conduct a series of periodic nighttime measurements of stratospheric aerosols in the vicinity of Menlo Park, California, by the use of a ground-based lidar containing both a pulsed ruby laser and a tunable dye laser. These measurements will be conducted over an 18-month period and will consist of approximately 100 instrumented observational hours spread throughout the period. A series of measurements during the hours immediately after sundown and preceding dawn will be included to ascertain the effects of sunlight on the concentration and vertical distribution of aerosols. The observations will also be scheduled, when possible, to coincide with aircraft, rocket, or balloon data-gathering operations in the local area. Data will be reduced and analyzed, and the results will continuously be reviwed to see if any changes in the frequency of observations or of the operating conditions are desirable. 
This semiannual report presents the results of all successful measurements made since the beginning of the observation program in October 1972 through June 1973. The results of each observation are presented as vertical profiles (with a resolution of $250 \mathrm{~m}$ to $500 \mathrm{~m}$ in altitude $\mathrm{z}$ ) of two quantities indicative of stratospheric aerosol content.

- The "scattering ratio," $R(z)$, equal to the ratio of total (molecular plus particulate) atmospheric backscattering coefficient to molecular backscattering coefficient.

- The aerosol backscattering coefficient, $f_{A}(z)$ (per meter per steradian).

Both the scattering ratio and the aerosol backscattering coefficient are integrated optical quantities determined by the number, size distribution; shape, and index of refraction of the aerosol particles lying within the stratospheric volume at altitude $z$ that is sampled by the lidar beam. As such, they cannot be converted to unambiguous values of particle number or mass concentration without auxiliary information on particle size distribution, shape, index of refraction and mass density. This auxiliary information may be obtained concurrently with the lidar measurements by means of direct sampling equipment on aircraft or balloon platforms. Alternatively, typical values of these auxiliary data as inferred from a representative direct sampling program may be used to convert the lidar data. The advantage of the lidar over the direct sampling techniques lies of course in its ability to rapidly observe stratospheric regions of large vertical extent, in the fact that it does not alter the quantities that it is sampling, and in its significantly lower cost per observation.

Even without the auxiliary data or assumptions necessary to convert them to absolute number or mass concentrations, the lidar data provide direct information on stratospheric aerosol content. The profiles of scattering ratio and aerosol backscattering coefficient immediately reveal 
the presence, altitude, and variability (in space and time) of strato- spheric aerosol layers. As such, they provide a valuable input to to modeling and other studies that attempt to describe the dynamic, radiative, physical, and chemical processes responsible for natural and man-made changes in the stratosphere. For example, on the basis of the lidar observations presented in this report, the following can be concluded :

- The level of the tropopause (12 to $15 \mathrm{~km}$ at Menlo Park, California) appears to be a level of relative minimum aerosol content.

- The presence of a layer of relative maximum aerosol content near $20 \mathrm{~km}$ is evident in all the observations. The ruby lidar data for this layer show a particulate contribution to the atmospheric backscatter that is 10 to 15 percent of the molecular contribution. This may be compared with particulate contributions that were 50 to 100 percent of the molecular contribution during 1964 and 1965 when the Agung volcanic material was present in the stratosphere.

- The lidar data show large differences in the vertical distribution of the stratospheric aerosol from one observation period to the next. Both layered structures and vertical decreases at constant mixing ratio are apparent.

- The time variability of particulate backscatter within a single night also differs from one observation to another. On 4 January 1973, the change of lidar scattering ratio during the observation period was evidently negligible; whereas on 15 May 1973, a significant change in scattering profile occurred as the night progressed.

- Sequential ruby $(\lambda=0.6943 \mu \mathrm{m})$ and dye $(\lambda=0.5890 \mu \mathrm{m})$ lidar observations on the same night produced scattering ratio profiles having the same shape; however, the scattering ratios $R(z)$ at the shorter dye wavelength were consistently lower than those at the longer ruby wavelength. This confirms that the enhanced return from the 20 to $25 \mathrm{~km}$ layer is of a particulate origin rather than from an anomalously dense molecular layer. Differences between the particulate backscattering coefficient $f_{A}(z)$ at the two wavelengths are nearly within the uncertainty of the measurements, but the possible wavelength dependence suggested by 
this observation is consistent with size distributions for the stratospheric aerosol that other workers have measured and suggested.

- The lidar observations reveal a slight increase in the aerosol backscattering coefficient of the $20-\mathrm{km}$ layer from $2 \times 10^{-9}$ per meter per steradian in October 1972 to $6 \times 10^{-9}$ per meter per steradian in May and June 1973. On the assumption that the optical (chemical) properties, shape, and size distribution of the particulates in this layer remained constant, the observed increase indicates that the particle number density increased by a factor of 3 .

- The largest variability in particulate backscatter was observed between 25 and $30 \mathrm{~km}$. In the 25 to $27.5-\mathrm{km}$ layer, the lidarobserved aerosol backscattering coefficient showed a decrease by a factor of 10 from December 1972 to mid-January 1973, followed by a tenfold increase from mid-January to April. Whether this variability was caused by a change in aerosol number density, an influx of large particles, or a significant change in the nature of the particulates cannot be determined at this time. However, the decrease of backscattering in the 25 to 27.5-km layer and a smaller decrease in the 22.5 to 25. 0-km layer coincide with a change in the zonal wind at those altitudes from a westerly to an easterly direction. Moreover, the subsequent increase in backscattering in those layers coincides with a return of the wind direction from easterly to westerly. This correspondence is suggestive of a physical mechanism responsible for the change in observéd particulate backscattering. Nevertheless, caution must be applied in interpreting this coincidence of wind and particulate variability because a subsequent change in zonal winds from westerly to easterly during April, May, and June was evidently not accompanied by a corresponding decrease in particulate backscatter. We will continue to observe the relationship of stratospheric winds and particulate backscatter to determine if significant correlations are present over a long period of time.

- On the basis of the lidar observations made during the past eight months, the conclusion is that large natural variations in the aerosol can be expected in the stratosphere. For example, if routine measurements of particulate mass loading were made between 25 and $30 \mathrm{~km}$, variations by a factor as large as 10 could be attributed to natural changes--at least when the concentrations are as low as those currently observed. 
- On the basis of the lidar backscatter data analyzed so far, the existence of a stratospheric aerosol extinction model much less than the E1terman (1968) model should be considered. (For a detailed discussion, see Appendix). This conclusion may have important implications in the development of stratospheric radiative transfer models.

The lidar observational program will continue in order to provide additional information on the presence, height, and variability of aerosol scattering layers in the natural stratosphere. Continuing improvements in our analysis procedures will accompany this observational program to ensure that correct inferences as to stratospheric aerosol variability are made. The Appendix presents a review of possible pitfalls in data analysis that become important when stratospheric aerosol content attains its current low levels and when the vertical extent of observations is large. 
Table 1 gives the parameters of the lidar system used in the observational program. The ruby laser system has an energy output of 1 to 2 $\mathrm{J} /$ pulse, at the wavelength $\sim 6900 \AA$ and a pulse duration of $<30 \mathrm{~ns}$ (pulse length $<4.5 \mathrm{~m}$ ); it is Q-switched and can transmit single pulses at a rate of 1 pulse every 2 to $3 \mathrm{~s}$. The dye laser system has an energy output of 100 to $150 \mathrm{~mJ} / \mathrm{pulse}$ at the wavelength of $\sim 5890 \AA$ and a pulse duration of $300 \mathrm{~ns}$ (pulse length $45 \mathrm{~m}$ ); it can transmit single pulses at a rate of 1 pulse every $4 \mathrm{~s}$. The receiver consists of a 16 in. Cassegrain telescope. Additional details on the equipment and the signal recording technique were given in a previous report [Viezee et al., 1973a].* Ruby lidars of the type used in the observational program are used for upper atmospheric observations by several research groups within the United States and abroad.

$*$ * All references are listed at the end of this report. 
Table 1

LIDAR SYSTEM PARAMETERS

Equipment

Ruby transmitter
Wavelength
Energy/pulse
Pulse duration
Pulse frequency
Beam diameter
Beam divergence
Dye transmitter
Wavelength
Energy/pulse
Pulse duration
Pulse frequency
Beam diameter
Beam divergence
Receiver
Diameter
Unobscured area
Acceptance cone
Filter bandwidth
Filter transmission
Separation from 1 aser
Beam overlap
Pul

\section{Parameters}

$6943 \AA$ (ruby)

1-2 Joules

$<30$ ns (q-switched).

$0.5 \mathrm{~Hz}$ (I pulse every 2 seconds)

6 inches (expanded)

$0.5 \mathrm{mrad}$ (full angle)

$5890 \AA$

100-150 $\mathrm{mJ}$

$300 \mathrm{~ns}$

$0.25 \mathrm{~Hz}$ ( 1 pulse every 4 seconds)

5 inches

$0.5 \mathrm{mrad}$ (full angle)

16 inch (Cassegrain)

$1070 \mathrm{~cm}^{2}$

$2 \mathrm{mrad}$ (full angle)

$10 \AA$

$50 \%$

$7 \mathrm{~m}$

height $>8 \mathrm{~km}$ 


\section{I DATA ANALYSIS AND INTERPRETATION}

\section{A. Method of Analysis}

The lidar backscatter data for a single observation period are obtained by integrating the return signals from up to 1000 single-pulse transmissions. This signal integration takes approximately 1 hour, covering the height region from 10 to $30 \mathrm{~km}$. The returns are integrated to reduce the sampling error in any range bin to $<2$ percent. Thus, the measured backscatter signals are determined with a high degree of accuracy.

Figure 1 shows the three principal steps in the analysis of the recorded backscatter data. The first step [Figure l(a)] consists of matching the measured (range-corrected) vertical profile of lidar backscatter signals (indicated by the solid curve) with a computed vertical profile of molecular backscatter (indicated by the dashed curve). The measured profile of backscatter data has an error of only 1 to 2 percent and a height resolution of $250 \mathrm{~m}$ up to $25 \mathrm{~km}$ and 300 to $500 \mathrm{~m}$ above $25 \mathrm{~km}$. The profile of molecular (Rayleigh) backscatter is computed by using an assumed vertical profile of atmospheric attenuation [El terman, 1968], and a measured vertical distribution of molecular number density corresponding to the Oakland radiosonde data nearest in time to the lidar observation period. (Oakland is approximately 20 miles north of Menlo Park.) The matching of the two profiles clearly shows a large bulge in the measured profile near $20 \mathrm{~km}$, and it must be attributed to a significant contribution to the atmospheric backscatter from particulate matter. 
(a) "MATCHING" OF MEASURED AND COM PUTED BACKSCATTER PROFILES

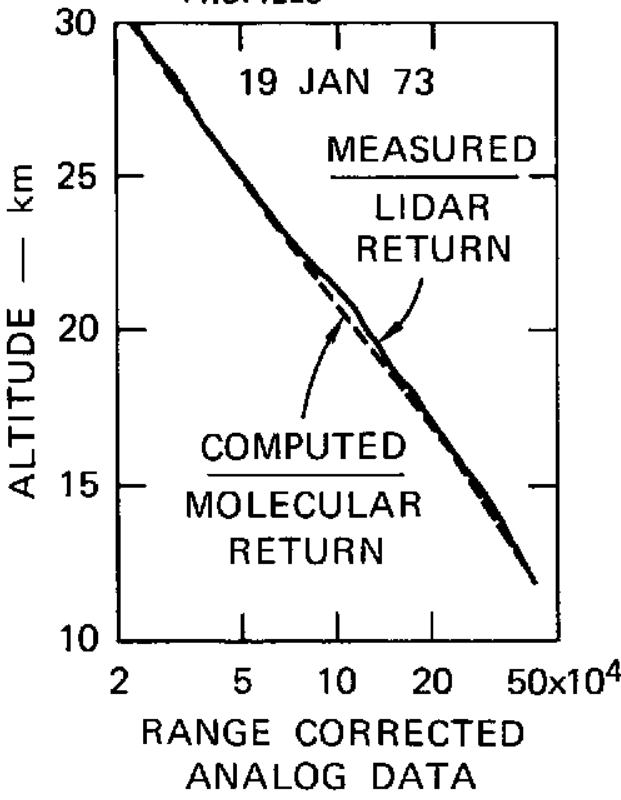

(b) VERTICAL PROFILE OF SCATTERING RATIO, R(Z)

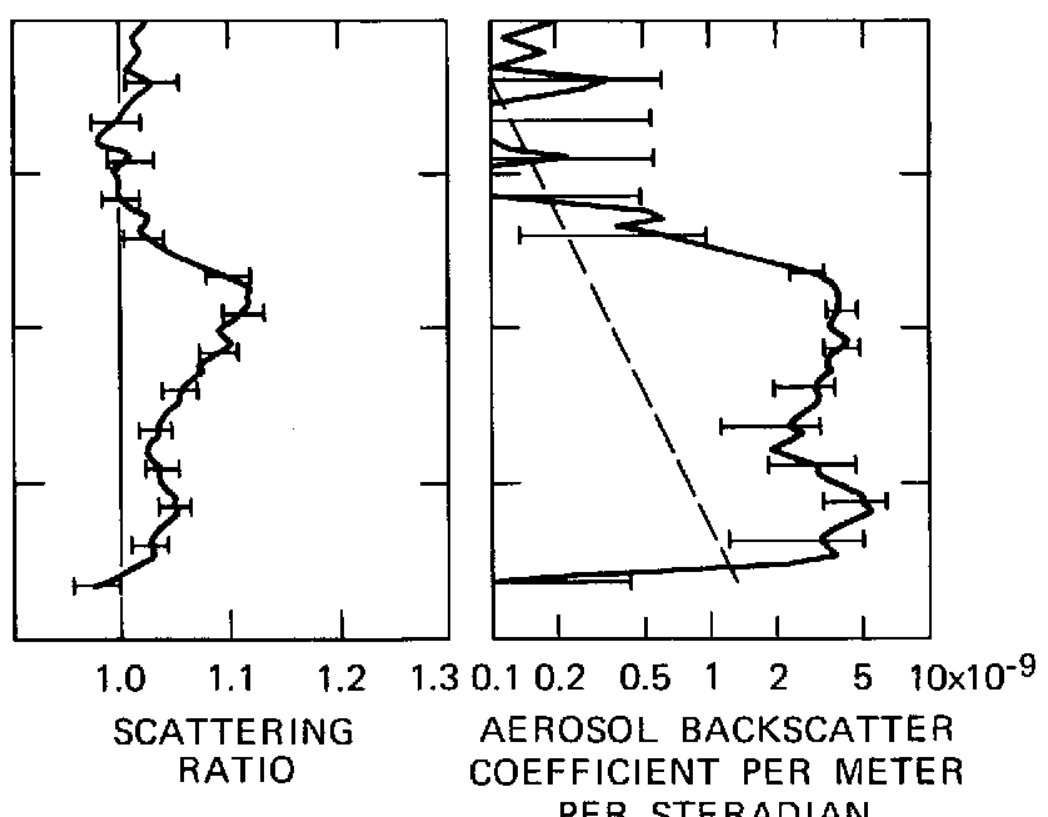

FIGURE 1 DATA SAMPLE SHOWING THE THREE PRINCIPAL STEPS IN THE ANALYSIS OF THE RECORDED LIDAR BACKSCATTER MEASUREMENTS 
As described in the Appendix and also in a previous report [Viezee, et al., 1973a], the "matching" method of analysis entails multiplying the computed molecular backscatter profile by a constant that cannot be determined before the lidar measurement is made. (The constant is unknown both because the lidar is uncalibrated and also because the transmission of laser energy through low-level haze and cirrus is not accurately known.) In the analysis of each lidar observation, this constant is determined in the following. manner. First, an arbitrary value for the constant is assumed; the resulting molecular backscatter profile is' used to compute a profile of the scattering ratio, $R(z)$, equal to the measured lidar return divided by the computed molecular return at altitude $z$. Then, an average scattering ratio is computed for all those data points with a scattering ratio that is within error bars ( \pm one standard deviation) of the minimum ratio. The constant is then adjusted so that this "average minimum ratio" becomes equal to one, and all individual scattering ratios are recomputed by using the adjusted value of the constant. This procedure effectively matches the computed molecular backscatter profile to the measured lidar backscatter profile in the region of minimum scattering ratio, and it is equivalent to assuming that the particulate content of that region is nil or negligible. As is shown in the Appendix and in a previous report [Viezee, et al., 1973a] if such a "molecular layer" indeed exists in the region of lidar analysis and if the molecular backscatter profile is accurately computed, the resulting scattering ratios then satisfy

$$
R(z)=1+\frac{f_{A}(z)}{f_{M}(z)} \text {, }
$$

where $f_{A}(z)$ is the particulate or aerosol backscattering coefficient, and $f_{M}(z)$ is the molecular (Rayleigh) backscattering coefficient. 
The resulting vertical variation of the scattering ratio is shown in Figure 1(b). The presence of an aerosol layer near $20 \mathrm{~km}$ shows very clearly in these data. As discussed in the First Quarterly Report [Viezee, et al., 1973a], the scattering ratio measurement is subject to errors arising principally from three sources:

- Statistical variation in the measured lidar return

- Errors in the measured radiosonde density profile

- Differences between the actual stratospheric transmission and that assumed [Elterman, 1968] in computing the molecular return.

The latter two sources of error are also discussed in more detail in the Appendix of this report. The total error ( \pm one standard deviation) in the scattering ratio amounts to approximately 2 percent, and is given by the error bars shown in Figure l(b), plotted at every fifth data point. The scattering-ratio data of Figure l(b) can be interpreted as follows: Around $25 \mathrm{~km}$, the data points are distributed within error bars of unit scattering ratio, which means that the aerosol backscattering coefficient is at most 2 percent of the molecular backscattering coefficient. In other words, the aerosol content in this layer is negligible within the uncertainty of our measurement. At the peak of the aerosol layer near $20 \mathrm{~km}$, the contribution of particulate matter of atmospheric backscatter is 10 percent of the contribution from gas molecules. This contribution decreases to 5 percent at $14 \mathrm{~km}$ and decreases further to less than 2 percent near $12 \mathrm{~km}$. The 12-km level coincides with the level of the tropopause.

The third step in the data analysis is with the use of Eq. (1) to express the scattering ratio in terms of the aerosol backscattering coefficient $f_{A}(z)$. The resulting vertical profile of this parameter is shown in Figure l(c). At the height of the layers of maximum aerosol content, values of the aerosol backscattering coefficient range from 
2 to $5 \times 10^{-9}$ per meter per steradian. When a Junge-type size distribution in the range from 0.1 - to $3.0-\mu m$ particle radius is assumed, these values correspond to 0.5 to 1.0 particle per $\mathrm{cm}^{3}$. The aerosol content above $25 \mathrm{~km}$ appears insignificant in this observation. The dashed line represents constant mixing ratio and is drawn at 1 percent of the molecular backscattering coefficient. It can be seen that in this data sample the particulates are distributed in a layered structure rather than according to constant mixing ratio.

Determination of the aerosol backscattering coefficient is as far as we can carry the analysis of independent lidar observations. Since the backscattering coefficient is an integral quantity that depends on the number density, the size distribution, and the optical properties of the particles, the lidar backscatter data alone obviously cannot provide unambiguous information on refractive index, size, or number concentration. The objective of our program, however, is not to provide such information but rather to give data on the space and time distribution of the aerosol. This information is obtained with a high degree of accuracy from the lidar observations as shown in Figures 2 and 3 .

\section{B. Summary of Data}

Figure 2 shows vertical profiles of the scattering ratio $R(z)$ for all 16 successful observations made in our program from October 1972 through June 1973. The presence of a layer of particulate matter near $20 \mathrm{~km}$ is clearly shown. However, differences in the vertical structure of this aerosol scattering layer are evident. For example, for 19 January, this layer is rather narrow with a secondary maximum near $14 \mathrm{~km}$; while for 27 March and 2 April, the layer is much broader, and the particulates appear to be more uniformly distributed around the 20-km level. A1so, for 2 Apri1, 15 May, and 12 June, a significant 

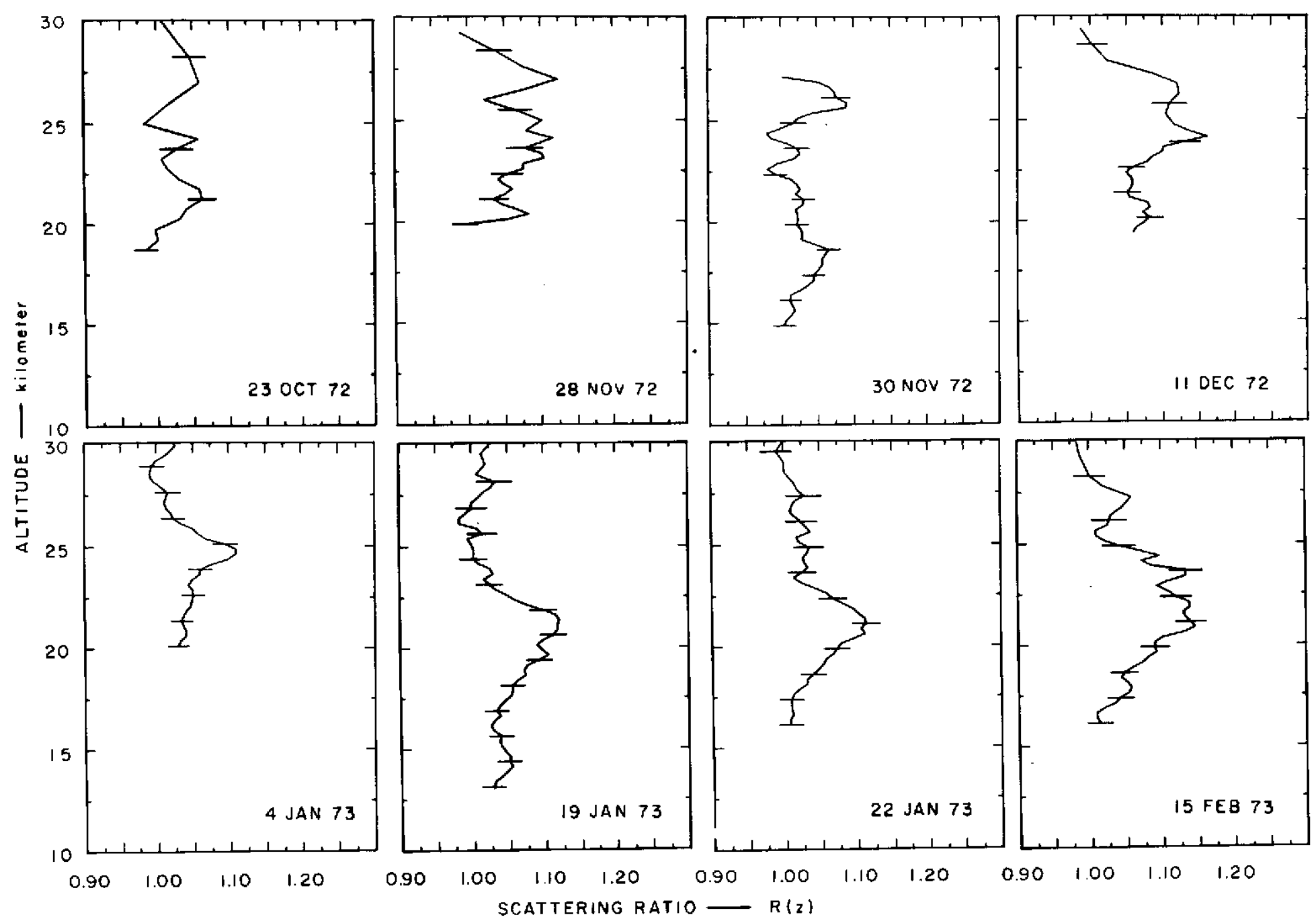

FIGURE 2a TIME SERIES OF SCATTERING RATIO, R(Z), VERSUS HEIGHT ANALYZED FROM LIDAR BACKSCATTER OBSERVATIONS MADE AT MENLO PARK, CALIFORNIA

Error bars represent \pm one standard deviation of the data sample (shown at every fifth point). 


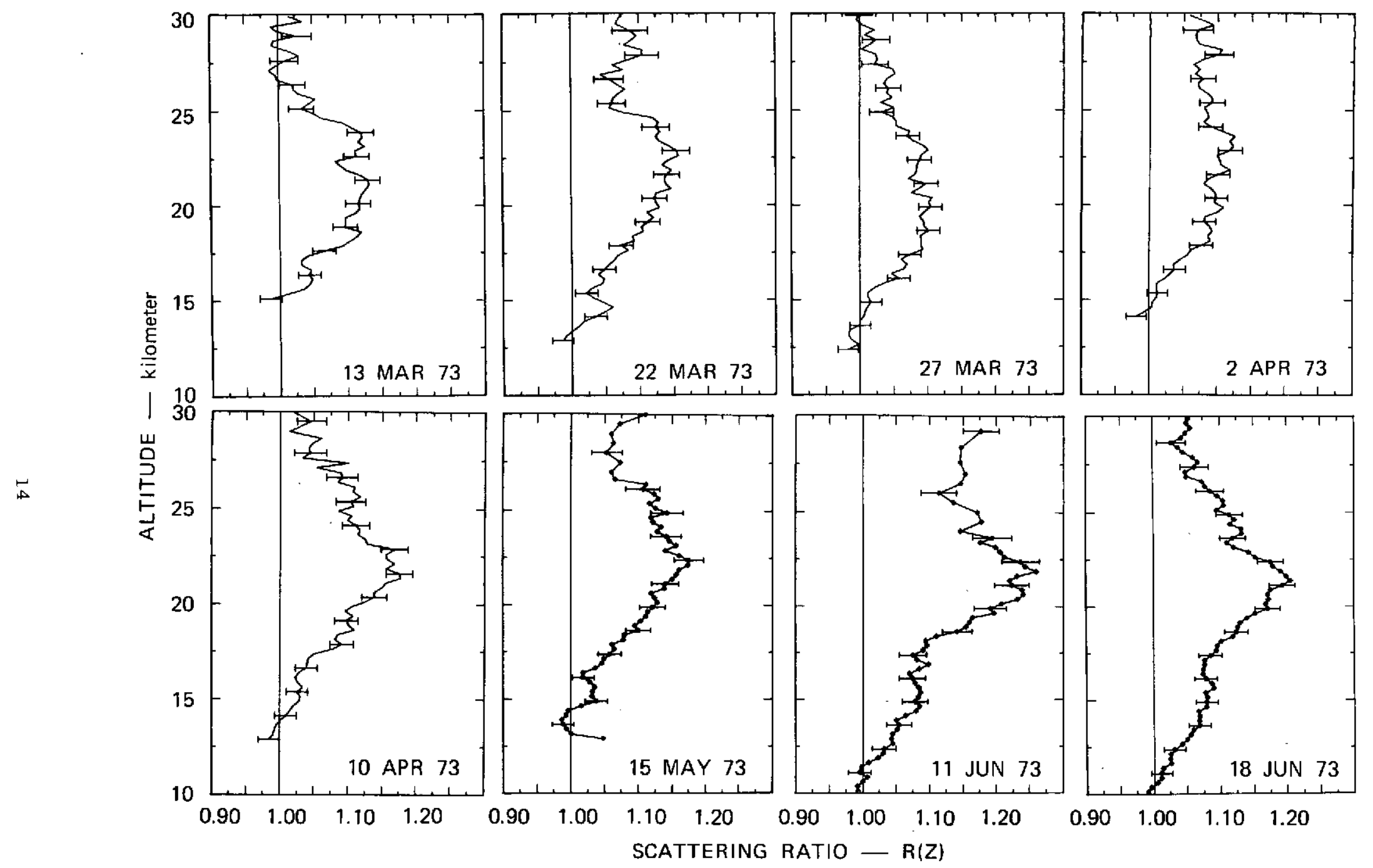

FIGURE $2 b$ TIME SERIES OF SCATTERING RATIO, R(Z), AS A FUNCTION OF HEIGHT, ANALYZED FROM LIDAR BACKSCATTER OBSERVATIONS MADE AT MENLO PARK, CALIFORNIA

Error bars represent \pm one standard deviation of the data sample (shown at every fifth point). 


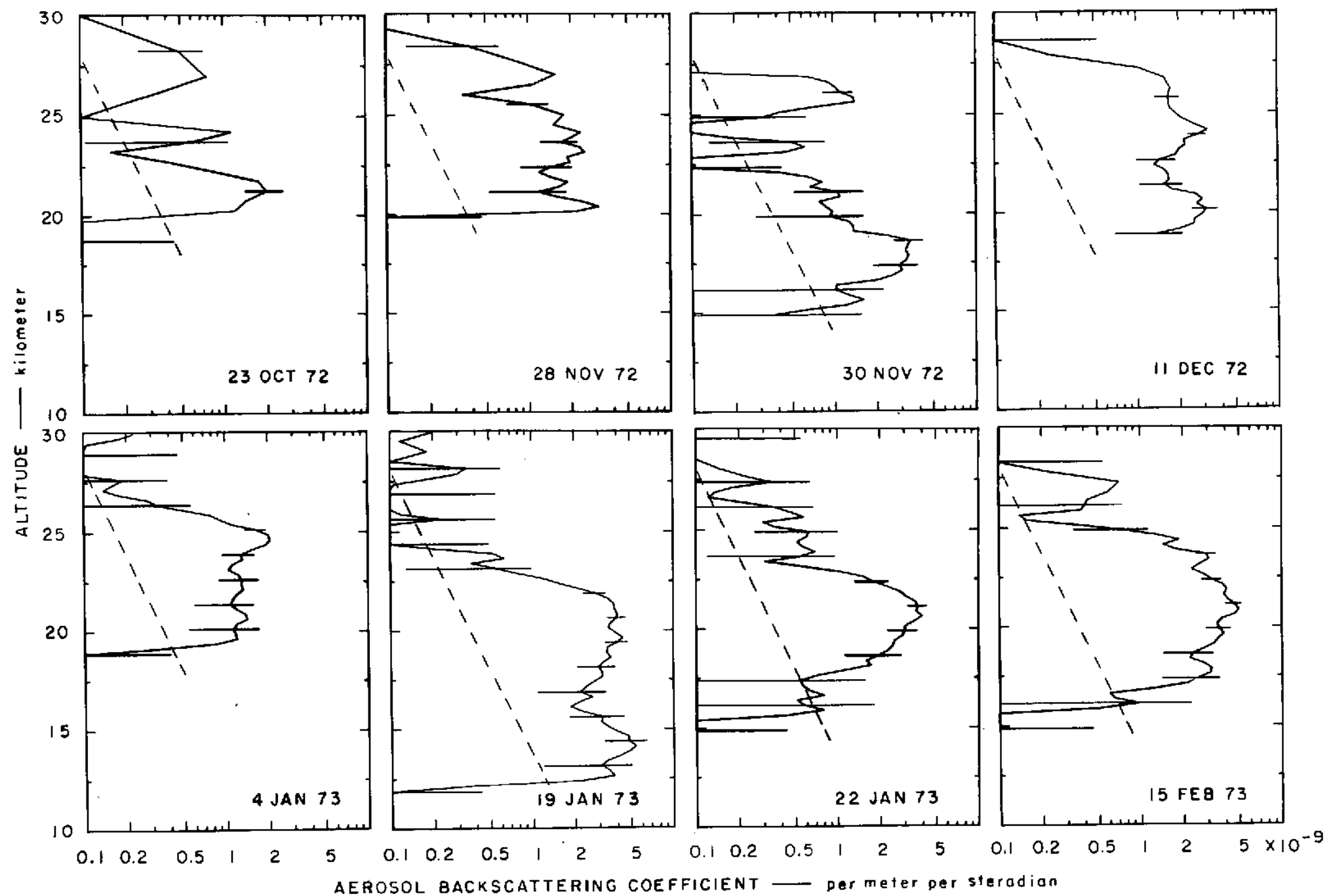

FIGURE 3a TIME SERIES OF AEROSOL BACKSCATTERING COEFFICIENT $f_{A}$, VERSUS HEIGHT COMPUTED FROM LIDAR BACKSCATTER OBSERVATIONS MADE AT MENLO PARK, CALIFORNIA

Error bars represent \pm one standard deviation of the data sample. Dashed line represents constant mixing ratio.

(Drawn at 1 percent of the molecular backscattering coefficient) 

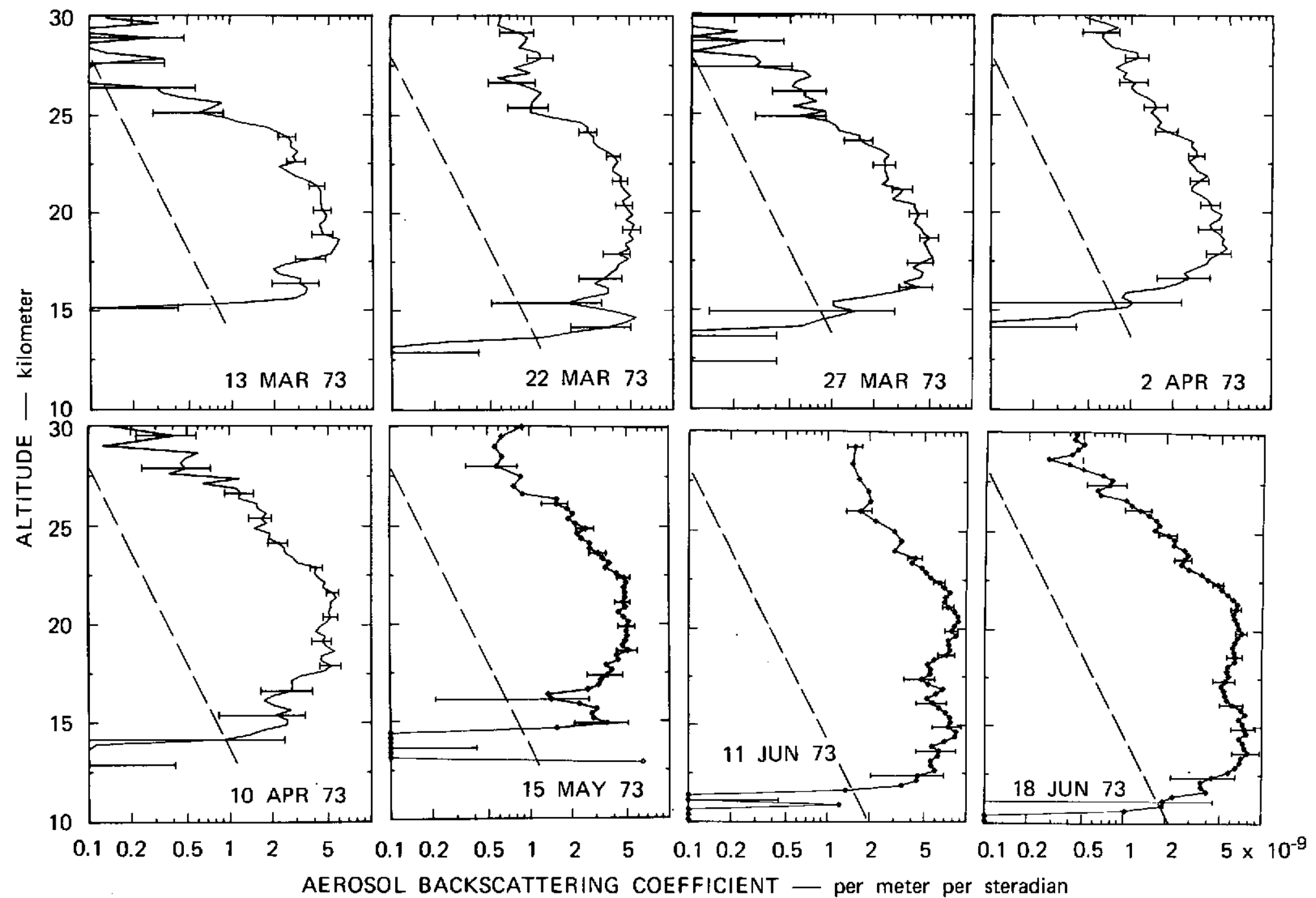

FIGURE 3b TIME SERIES OF AEROSOL BACKSCATTERING COEFFICIENT $f$, AS A FUNCTION OF HEIGHT, COMPUTED FROM LIDAR BACKSCATTER OBSERVATIONS MADE AT MENLO PARK, CALIFORNIA

Error bars represent \pm one standard deviation of the data sample. Dashed line represents constant mixing ratio.

(Drawn at 1 percent of the molecular backscattering coefficient) 
increase can be seen in the aerosol backscatter at $25 \mathrm{~km}$ and above. The aerosol scattering layer near $20 \mathrm{~km}$ is associated with peak values of the scattering ratio of 1.10 to 1.15 ; this means that the aerosol backscattering coefficient is only 10 to 15 percent of the molecular backscattering coefficient. This situation is very different from that during the mid-1960s, when the Agung volcanic matter was still present in the stratosphere. For example, Grams and Fiocco (1967) made lidar observations in 1964 and 1965 and found typical values of the scattering ratio in the range 1.5 and 2.0 ; this means that during those years, the particulate contribution to atmospheric backscattering was 50 to 100 percent of the molecular contribution. The data of Figure 2 show a particulate contribution that is only 10 to 15 percent of the molecular contribution.

Figure 3 shows the corresponding vertical profiles of the aerosol backscattering coefficient. These profiles again show the difference in the aerosol distribution between the various observation periods. Significant aerosol variations appear at $25 \mathrm{~km}$ and above. Also, the lidar data sometimes suggest a layered structure (for example, those for 19 January); while at other times, the vertical profile resembles constant mixing ratio (for example, that for 2 April). In all cases, the level of the tropopause (12 to $14 \mathrm{~km}$ ) appears to be sink region. The observed variations in aerosol backscattering coefficient are discussed further in connection with stratospheric wind data in Section III-E below.

C. Sequential Ruby and Dye Lidar Observations

On 15 May 1973, observations were made by using first the ruby laser $(\lambda=0.6943 \mu \mathrm{m})$ transmitter of the lidar system and immediately thereafter by using the dye laser $(\lambda=0.5890 \mu \mathrm{m})$ transmitter. The results 
are shown in Figure 4. As can be seen from Figure 4(a), the observations at both wavelengths reveal a scattering ratio profile of similar shape; however, the values at the shorter dye wavelength fall consistently below those at the ruby wavelength. This is in accord with the $\lambda^{-4}$ dependence of molecular (Rayleigh) backscattering and the expected weaker $\lambda^{-\alpha}$ dependence of particulate backscattering [typically observed values are $\alpha=0-2$; for example Elterman's (1968) model uses $\alpha \approx 0.9]$. Thus, at the shorter dye wayelength, molecular scattering may be expected to be relatively more important than particulate scattering when compared with the relative amounts of scattering at the longer ruby wavelength. This expected behavior is indeed observed in Figure 4(a) and confirms the fact that the enhanced backscattering in the 18 to $25-\mathrm{km}$ region does not result from an anomalously dense molecular layer (which would give scattering ratios independent of wavelength) but must be of particulate origin. In addition, the fact that the scattering ratio profiles have the same shape tends to validate the radiosonde data used in the computation of the scattering ratios.

The wavelength dependence of the particulate backscattering coefficient may be simply related to the particle size distribution $\mathrm{n}(r)$ ( $\mathrm{r}$ is . particle radius) provided that the size distribution is of the form

$$
n(r)=K_{1} r^{-(\nu+1)}
$$

throughout the optically significant size range. If this is the case, it can easily be shown [see, e.g., Junge (1963), p. 142] that

$$
\mathrm{f}_{\mathrm{A}}=\mathrm{K}_{2} \lambda^{-\alpha}
$$




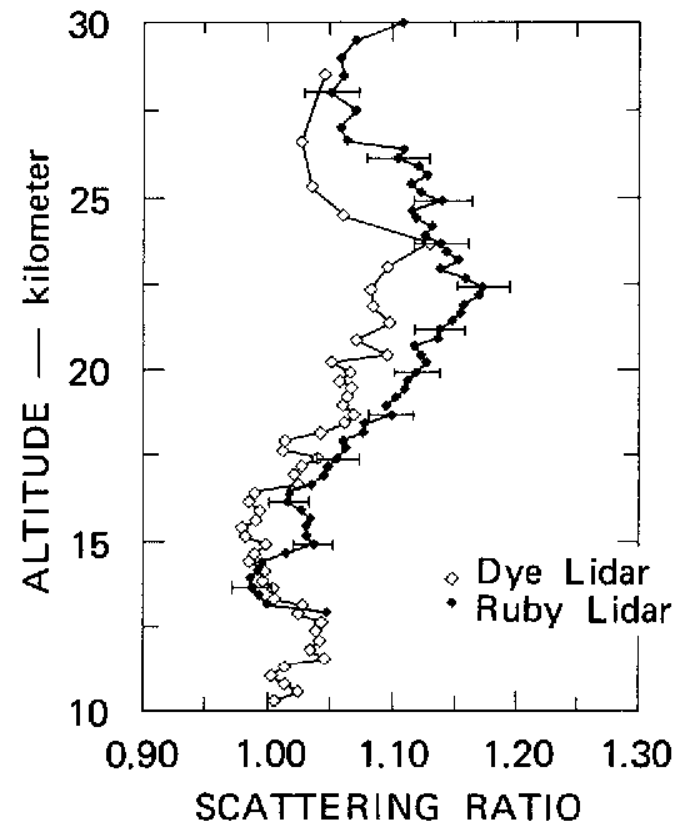

(a)

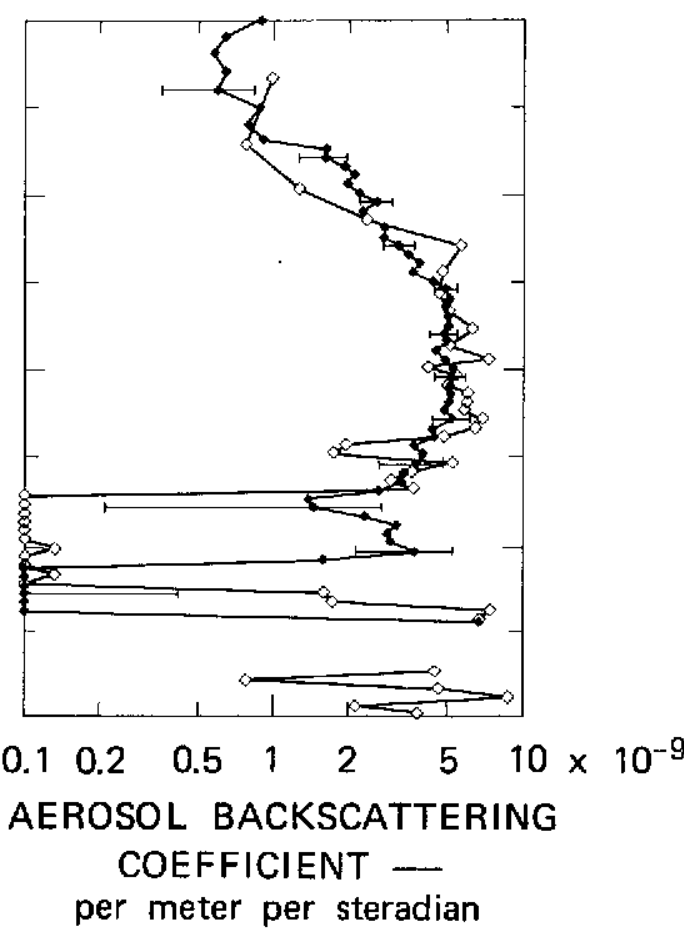

(b)

FIGURE 4 COMPARISON OF LIDAR PROFILES MEASURED WITH RUBY TRANSMITTER $(\lambda=0.6943 \mu \mathrm{m})$ AND DYE TRANSMITTER $(\lambda=0.5890 \mu \mathrm{m})$ AT MENLO PARK, CALIFORNIA, ON 15 MAY 1973

(a) Scattering ratio; (b) Aerosol backscattering coefficient. 
and

$$
\alpha=v-2 .
$$

In these equations, $K_{1}$ and $K_{2}$ are constants proportional to the particle number concentration, and $\nu$ is a single parameter giving the dependence of particle number on radius. As can be seen from Figure 4(b), the 15 May 1973 observation is inadequate to make an accurate determination of the wavelength exponent $\alpha$ because the ruby and dye values do not generally differ from each other by more than the uncertainty of the respective measurements. Within that uncertainty, however, the wavelength dependence of $f_{A}$ shown in Figure $4(b)$ is consistent with values of $\alpha=-0.5$ to +1.0 . These correspond to size distribution exponent values of $\nu=1.5$ to 3 , which are consistent with values observed experimentally [Junge, et al., $1961(\nu \approx 1.5$ to 3$)]$, and also with values expected on the basis of theoretical considerations [Friedlander, 1961 $(v=1$ to 3$)]$. These results are somewhat encouraging, but primarily they tend to emphasize the need for somewhat higher precision in the acquisition and analysis of stratospheric lidar data if useful wavelength dependences and size distribution information are to be extracted.

\section{Time Variability of Scattering Profiles Within Nightly Observations}

On several occasions, we have compared the scattering profiles obtained at different times within the same night. The results of two such comparisons are shown in Figure 5. The case of 4 January 1973 shown in Figure 5(a) is fairly typical in that any differences between the two profiles are within the uncertainty of the measurement. An unusual case, however, is that of 15 May 1973, shown in Figure 5(b). As can be seen, the particulate backscattering appears to have increased 

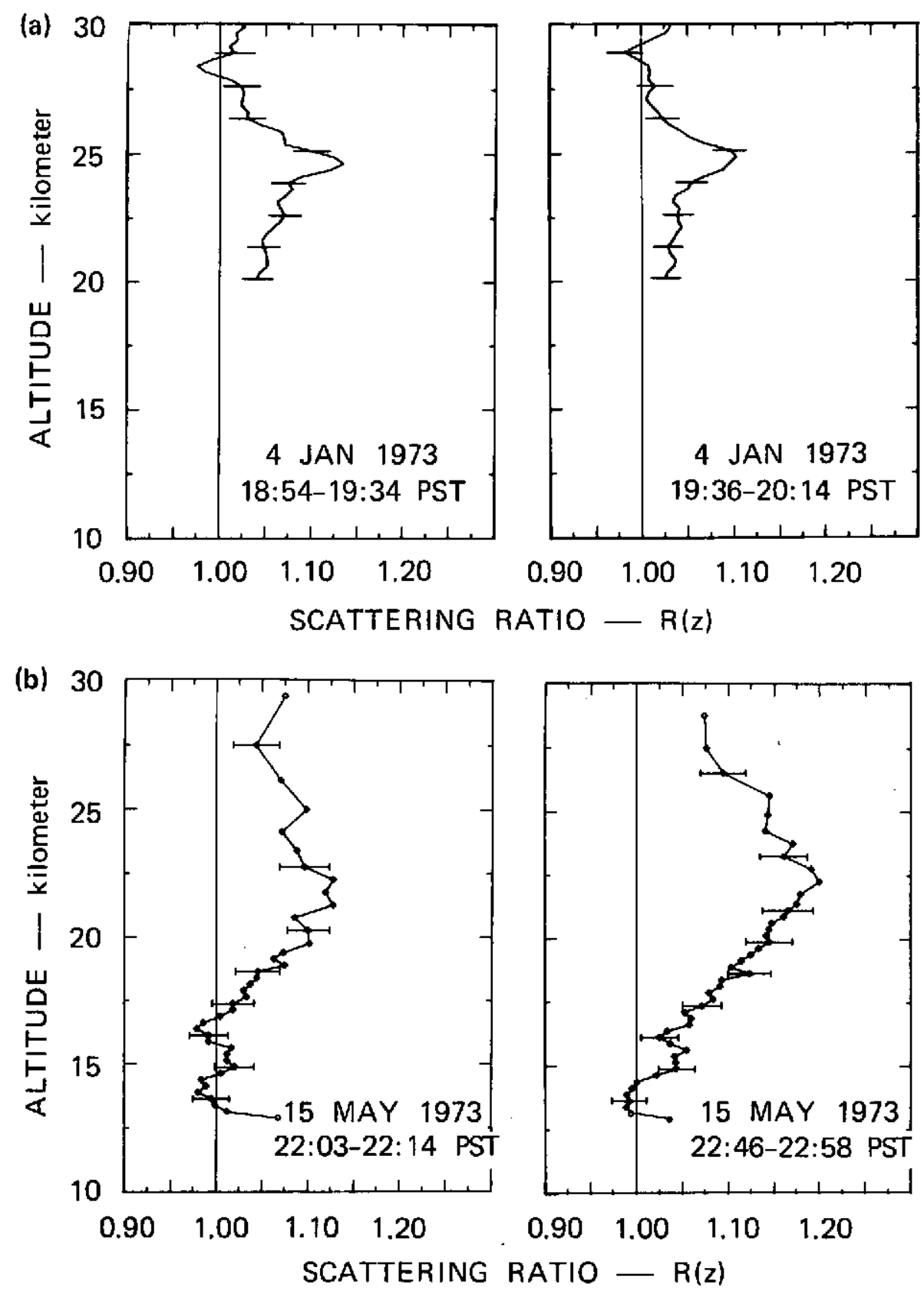

FIGURE 5 TIME VARIATIONS OF SCATTERING RATIO OCCURRING WITHIN NIGHTLY LIDAR OBSERVATIONS MADE AT MENLO PARK, CALIFORNIA

(a) 4 January 1973; (b) 15 May 1973 
significantly from the first observation to the second. This conclusion should be adopted with some caution, however, since the "matching" method of analysis would produce the same time variation in scattering ratio if the particulate concentration at 13 to $14 \mathrm{~km}$ were nonnegligible in the early observation and decreased thereafter. The presence of an obvious band of cirrus at $12.5 \mathrm{~km}$, which gave scattering ratio values off the scale of the figure and was not present on any other night of observations, may in fact be related to changing particulate backscatter in the 13 to 14-km region.

E. Time Variability of Scattering Profiles and Stratospheric Winds: October 1972-June 1973

Figure 6 summarizes all the lidar observations made during the period October 1972 through June 1973. To summarize these data, four layers of $2.5-\mathrm{km}$ thickness were selected between $20 \mathrm{~km}(65,000 \mathrm{ft})$ and $30 \mathrm{~km}(98,000 \mathrm{ft})$. For each layer, the mean* value of the aerosol backscattering coefficient measured during each observation period is indicated along with an exror bar that includes the sampling error in the measured lidar signal but not the possible errors resulting from incorrect atmospheric density or extinction profiles (see also discussion below and in the Appendix). When these observed data points were connected by straight lines, profiles of atmospheric backscatter as a function of time were obtained; on this basis, the lidar observations can be interpreted in terms of the spatial and temporal variability of the particulates. In the 20.0 to $22.5-\mathrm{km}$ layer, the lidar data show an increase in the aerosol backscattering coefficient from $2 \times 10^{-9}$ per meter per

* Note that this differs from the maximum values plotted in Figure 4 of the Second Quarterly Report [Viezee et al., 1973b]. The shape of the resulting curves, however, is very similar. 


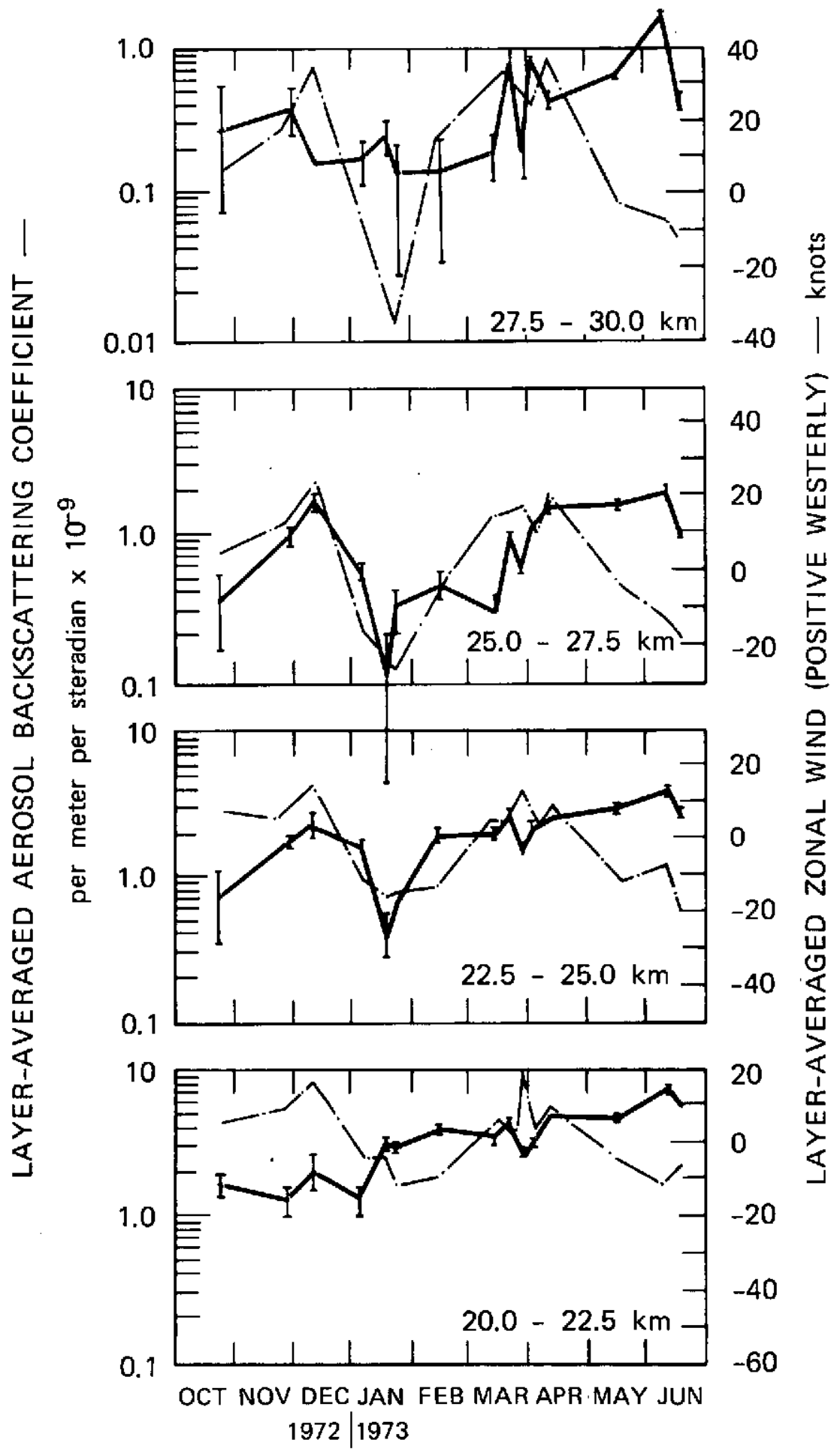

FIGURE 6 TIME VARIABILITY OF LAYER-AVERAGED AEROSOL BACKSCATTERING COEFFICIENT (HEAVY LINE) AND ZONAL WIND (LIGHT LINE) FOR FOUR ALTITUDE REGIONS 
steradian in October 1972 to $6 \times 10^{-9}$ per meter per steradian in May and June 1973. If the chemical properties of the aerosols and their shape and size distribution remained constant in this stratospheric layer, this increase indicates that the mass loading increased by a factor of 3 .

The data profile in the 22.5 to $25.0-\mathrm{km}$ layer shows a similar slight increase in addition to a short-period decrease in January. This sudden decrease is based on the data points from three observation periods. The largest variations in atmospheric backscatter are found in the 25.0 to $27.5-\mathrm{km}$ layer. For the period from October to December 1972, a definite increase in aerosol backscattering coefficient is observed. A much larger increase in lidar scattering ratio was observed at the same time in Japan and has been related to an influx of dust from the comet Giacobini-Zinner [Hirono et al., (1972)]. However, as discussed below, other mechanisms may be responsible for the increase that we have observed. For the period from December 1972 to mid-January 1973, the aerosol backscattering coefficient in the 25.0 to 27.5-km layer shows a decrease by a factor of 10, followed by a tenfold increase from mid-January to April. The observed large variability could imply that the particle number density varied by a factor of 10 ; it could also imply that large particles were injected into this layer from mid-January to May or that the nature of the particles changed significantly. The layers at 22.5 to $25.0-\mathrm{km}$ and 27.5 to $30.0-\mathrm{km}$ show a similar large timevariability in aerosol backscatter.

The lidar observations alone cannot explain the origin of the observed variation, but comparisons with other atmospheric data frequently can be instructive in this regard. Accordingly, we have inspected the data on stratospheric winds measured in the vicinity of Pt. Mugu, California during the period of the lidar observations. Vertically averaged values for layers corresponding to those of the lidar data 
were computed for both zonal and meridional components of the winds. The zonal layer averages obtained in this manner are shown in Figure 6, plotted along with the aerosol backscattering coefficient. As can be seen, primarily for the layers 22.5 to $25.0 \mathrm{~km}$ and 25.0 to $27.5 \mathrm{~km}$, the December-January decrease in particulate backscatter coincides with a shift in zonal wind from a westerly to an easterly direction (this wind shift was associated with a sudden stratospheric warming observed at that time). Moreover, the subsequent shift in winds from easterly to westerly during February, March, and April was accompanied by increasing particulate backscatter. This comparison is suggestive of a physical relationship between stratospheric winds and the nature or concentration of aerosol content. A detailed interpretation is not fully justified at the present time, however, because the data comparison is limited in space and time. For example, Pt. Mugu is more than 200 miles SSE of Menlo Park and the wind measurements are obtained during daylight while the Ildar data are collected at nighttime. In addition, the wind shift from westerly to easterly in April-June was not accompanied by a corresponding decrease in particulate backscatter. As shown in the Appendix, however, use of a more realistic atmospheric extinction profile in our analysis may reduce the June backscatter values (which alone are based on a normalization at $10 \mathrm{~km}$ ) below the error bars of Figure 6, while the other values remain relatively unchanged. We will continue to observe the relationship of winds and particulate backscattering coefficients over a more extended period of time and to assess the effect on our data of assuming a reduced atmospheric extinction profile. The results of these investigations will be presented in forthcoming reports. 


\section{CONCLUSIONS}

The data presented in this report demonstrate that large natural variations can be expected in the stratospheric aerosol. Most important to CIAP is that the lidar observations suggest the presence of natural variations in particulate mass loading by a factor as large as 10 between 25 and $30 \mathrm{~km}$. Other conclusions that may be abstracted from the data have been summarized in Section $\mathrm{I}$.

The validity of the conclusions is supported by a recent experiment that consisted of a comparison between lidar data obtained by the lidar research group at NASA, Langley, and simultaneous balloon data obtained by the University of Wyoming [Dynatrend, 1973], A similar comparison has a1so been reported by Fernald et al. (1973).

If lidar observations of stratospheric aerosol scattering layers were made by a network of laser-radar stations, such a lidar network could effectively serve as a routine monitoring network when operated in conjunction with periodic "calibration" input on refractive index and size distribution from aircraft/balloon data. 


\section{Appendix \\ IMPORTANCE OF ASSUMED ATMOSPHERIC DENSITY AND EXTINCTION PROFILES IN THE ANALYSIS OF STRATOSPHERIC LIDAR DATA}




\section{Appendix}

\section{IMPORTANCE OF ASSUMED ATMOSPHERIC DENSITY AND \\ EXTINCTION PROFILES IN THE ANALYSIS \\ OF STRATOSPHERIC LIDAR DATA}

\section{Introduction}

A fundamental, derived quantity in the analysis of stratospheric lidar data is the "scattering ratio," $R(z)$, defined by

$$
R(z) \equiv \frac{f_{M}(z)+f_{A}(z)}{f_{M}(z)},
$$

where $f_{A}(z)$ is the aerosol or particulate backscattering coefficient, and $f_{M}(z)$ is the molecular backscattering coefficient, both at altitude $z$. In practice, the scattering ratio is obtained by means of the equation

$$
R(z)=\frac{S(z)}{M(z)}
$$

in which $S(z)$ is the measured range-corrected lidar backscatter signal and $M(z)$ is the range-corrected lidar signal that would result from a purely molecular layer at altitude $z$, calculated as

$$
M(z)=k^{\prime} f_{M}(z) q^{2}(z)
$$


In this equation, $\mathrm{k}^{\prime}$ is a lidar system calibration constant and $\mathrm{q}^{2}(\mathrm{z})$ is the two-way transmission of a laser signal between the lidar and altitude $z .^{*}$ The measured range-corrected lidar signal is given by

$$
S(z)=k^{\prime}\left[f_{M}(z)+f_{A}(z)\right]_{q}^{2}
$$

Thus, taking the ratio of Eq. (A.4) to Eq. (A.3), as dictated by Eq. (A.2), properly gives the scattering ratio $\mathrm{R}(\mathrm{z})$ defined by $\mathrm{Eq}$. (A.1), provided the quantities required in Eq. (A.3) to compute $M(z)$ are accurately known.

Because of the general difficulty of calibrating lidar systems, the calibration constant $k^{\prime}$ is usually unknown; therefore, the standard procedure for analyzing stratospheric lidar backscatter data in the altitude region of interest is to reference them to a molecular atmosphere. Typically this is accomplished by adjusting the value of $\mathbf{k}^{\prime}$ so that the statistically significant minimum ratio $R\left(z_{o}\right)$ is equal to unity. This procedure has been used by many investigators [Grams, 1966; Grams and Fiocco, 1967; Fox, et al., 1973; Melfi, et a1., 1973; Viezee, et al., 1973a], and is equivalent to assuming that the atmosphere at altitude $z_{0}$ is essentially molecular, with negligible particulate content (cf. Eq. A.1). Provided such a molecular layer actually exists in the region of lidar analysis, this procedure--in addition to eliminating the need for an accurate calibration--has the additional advantage of permitting analysis of lidar backscatter data even when cirrus clouds or low-level layers of atmospheric pollution introduce a large and unknown extinction below the altitude region of analysis. The

\footnotetext{
* Derivation of these equations is given in detail by Viezee et al. (1973a).
} 
possibility of nonnegligible dust content throughout the region of lidar analysis of course provides a source of potential error that workers in this field have long been aware of.

The purpose of this Appendix is to examine the potential errors in the other two quantities required in the computation of the expected molecular return (cf. Eq. A.3); namely, the molecular backscattering coefficient $f_{M}(z)$ and the two-way transmission $q^{2}(z)$. The magnitude of possible errors in these quantities is such that the resulting errors in inferred stratospheric particulate content are relatively small when particulate content is high, as was the case, for example, after the Agung volcano eruption in 1963, when the first stratospheric lidar observations were made [Fiocco and Grams 1964; Grams, 1966; Grams and Fiocco 1967]. At that time, typically observed maximum scattering ratios were in the neighborhood of $R=2.0$, indicating a particulate backscattering coefficient approximately equal to the molecular backscattering coefficient (cf. Eq. A.1). Since the time of these first observations, however, a general decrease in stratospheric aerosol content has been observed [Elterman, 1973; Fox et al., 1973]. Accordingly, typical maximum values of lidar scattering ratios measured in the past few years have been in the range $\mathrm{R}=1.10-1.15$ [Fox, et al., 1973; Melfi, et al., 1973; Viezee, et al., 1973a,b]. Thus, the size of the aerosol backscattering coefficient, given by

$$
f_{A}(z)=[R(z)-1] f_{M}(z),
$$

is now only about 10-15 percent of the molecular backscattering coefficient, indicating a decrease by about an order of magnitude since the peak concentrations of 1964-1965. As will be shown below, when the scattering ratio is of its current size, probable errors in the assumed 
molecular backscattering and two-way atmospheric transmission profiles can often result in significant errors in the computed particulate backscattering coefficient.

\section{Molecular Backscattering Profile}

The molecular backscattering coefficient $f_{M}(z)$ required in Eq. (A.3) is given by

$$
f_{M}(z)=C_{r} N_{M}(z),
$$

where $\mathrm{C}_{\mathbf{r}}$ is the Rayleigh backscattering cross section (dimensions: area/unit solid angle) for a single air molecule, and $N_{M}(z)$ is the molecular number density (number/unit volume) at altitude $z$. (The molecular backscattering coefficient thus has dimensions of inverse length/unit solid angle.) The atmospheric Rayleigh backscattering cross section $C_{r}$ is known to high accuracy and is constant over the region of stratospheric 1idar analysis [Elterman, 1968; Fox, et a1., 1973]. Thus, errors in $N_{M}(z)$ are the only source of errors in $f_{M}(z)$.

In many previous studies, values from standard atmospheres [see, e.g., U.S. Standard Atmosphere Supplements, 1966] appropriate to the season and location of the lidar observation have been used to compute $N_{M}(z)$. As is known, however, at any given date and location the actual stratospheric density profile may differ from the standard by several percent or more. When the scattering ratio is close to unity, these differences from the standard can result in significant changes in inferred particulate backscattering coefficient. 
These changes are illustrated in Figure A-1 for two cases of lidar observations made at Menlo Park, California. In each case, scattering ratios were computed by using molecular density profiles computed from two different sources:

- The Midlatitude Spring/Fall U.S. Standard Atmosphere [U.S. Standard Atmosphere Supplements, 1966].

- The Oakland, California radiosonde ascent made on the night of the lidar observation. [Oakland is approximately 20 miles north of Menlo Park.]

The Oakland radiosonde density profiles are presented in Figure A-1 (a, c) as percentage deviations from the U.S. standard density. The 19-20 January 1973 case is fairly typical of wintertime density soundings used in the present study. As can be seen from figure A-1(b), use of the radiosonde density profile introduces small but significant differences in the shape of the scattering ratio profile and, therefore, in the inferred structure of stratospheric aerosol layers as compared with that obtained by using the standard density profile. In regions where the scattering ratio is close to unity, the aerosol backscattering coefficient (cf. Eq. A.5) is changed by a factor of two or more.

The second case, that of 15-16 May 1973, illustrates an observation in which the deviation of the radiosonde density from the standard was quite large, amounting to nearly 12 percent in the vicinity of $13 \mathrm{~km}$. To ascertain that this observation was not the result of an isolated radiosonde malfunction, radiosonde profiles from ascents made 24 and 12 hours before and 12 and 24 hours after the 16 May 0400 (local standard time) ascent were inspected. This inspection revealed a smooth buildup and decline of the dense layer at $13 \mathrm{~km}$, with the density deviation at one time exceeding 12 percent. Although the magnitude of the density deviation observed on 16 May 0400 is unusually large, the occurrence of the dense, cold layer near $13 \mathrm{~km}$ is fairly typical of our late spring 

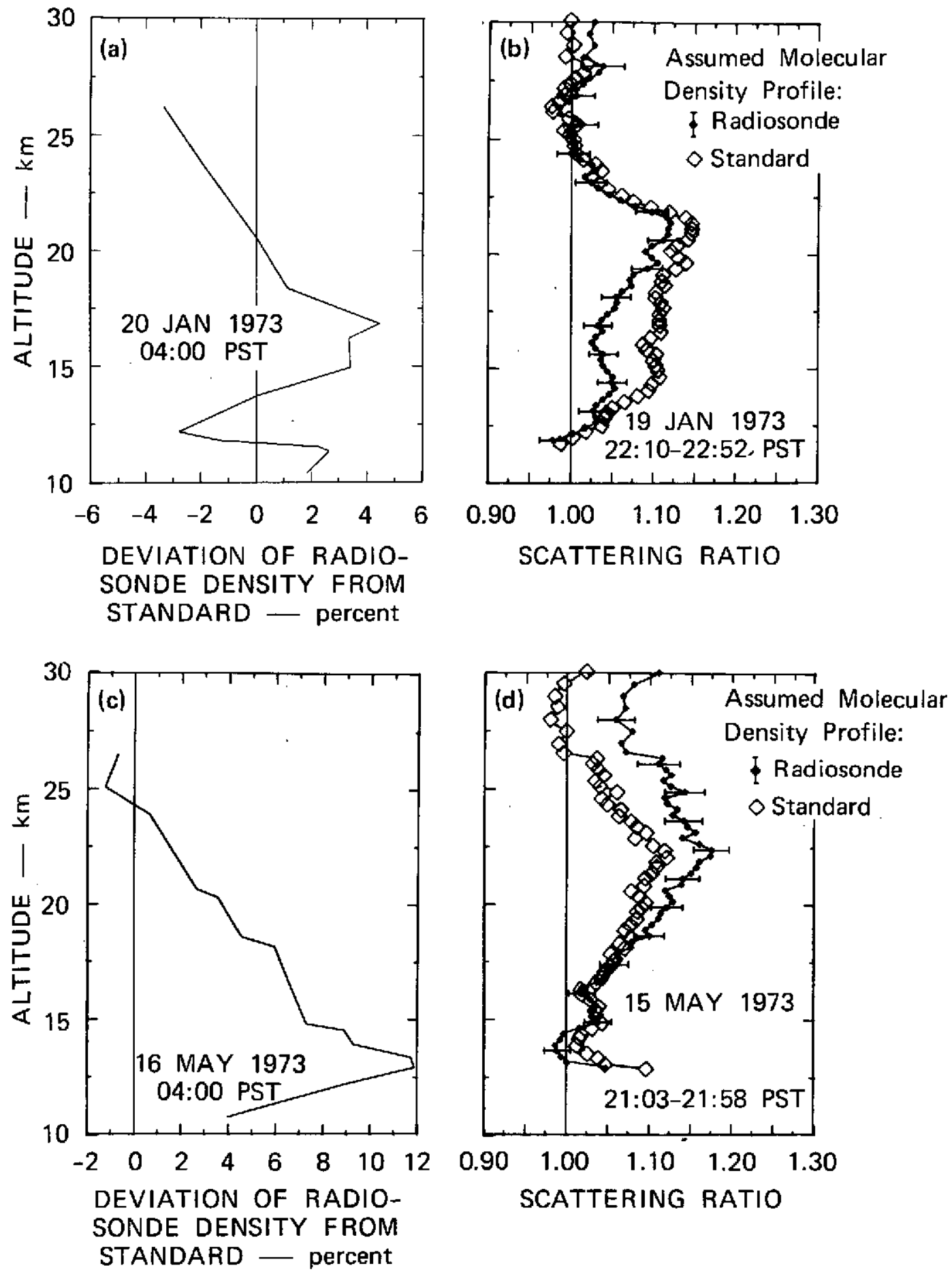

FIGURE A1 EFFECT ON LIDAR SCATTERING RATIO OF ASSUMING OAKLAND RADIOSONDE OR STANDARD (MIDLATITUDE SPRING-FALL) MOLECULAR DENSITY PROFILE

(a), (c) Radiosonde data; (b), (d) Scattering ratios obtained using radiosonde and standard profiles. 
and early summer observations, and indicates a rise of the tropopause at Oakland, California above the level of the standard. As expected, use of this radiosonde molecular density profile results in very significant changes in the shape of the scattering ratio profile, as shown in Figure $A-1(d)$.

Errors in the measured radiosonde density profile $N_{M}(z)$ will of course produce corresponding errors in the scattering ratio $R(z)$, but not if the radiosonde errors are systematic so that all number densities in the region of lidar analysis are affected by the same relative amount. This is true because of the method (discussed above) of "matching" the molecular return to the lidar return at an altitude within the range of observations. Errors in $R(z)$ will result from errors in $N_{M}(z)$ of one point within the region of analysis with respect to another; these errors are caused, for example, by random measurement error or instrumental drift during the radiosonde traversal of the layer being analyzed. We have estimated the magnitude of these possible errors [Viezee, et al., 1973a] at 1 percent, and they are included in the error bars on the scattering ratios of Figure A-1.

The importance of using a local density measurement, rather than a density standard, in the analysis of stratospheric lidar data has been noted by several other investigators. For example, Melfi, et al. (1973) used temperature and pressure sensors on a balloon flown concurrently with their lidar observations to obtain a density profile. They compared the 1idar-derived aerosol structure with that revealed by simultaneous in situ measurements made with a photoelectric particle counter on the same balloon. Agreement between the two measurements improved signiflcantly when the measured density profile was used in the lidar analysis instead of a standard. In connection with airborne lidar measurements, Schuster, et al. (1973) have suggested using a 
computer program that employs nearby radiosonde data and isentropic analysis to generate a molecular density field above the lidar flight path. The above discussion and examples are therefore presented mainly for the sake of concreteness and to illustrate the possible magnitude of errors that may be introduced by relying on a standard atmospheric density profile.

\section{Two-Way Transmission Profile}

Use of so called "standard" data to compute the two-way transmission $q^{2}(z)$ will introduce errors in $R(z)$ in a manner which is completely analogous to that described in the previous section (cf. Eq, A.3). If the actual transmission differs from the standard by more than one or two percent, these errors will be significant, in the case of the small scattering ratios currently being observed. Therefore, these transmission errors are investigated in more detail in this section, and several examples of their importance are presented. To our knowledge, these errors have not been taken into account by other researchers, but they have proved to be significant in our current studies.

The two-way transmission $q^{2}(\mathrm{z})$ required in Eq. (A.3) is given by

$$
q^{2}(z)=\exp \left[-2 \tau\left(z_{L}, z\right)\right]
$$

where $z_{L}$ is the altitude of the lidar system and $T\left(z_{L}, z\right)$ is the optical depth between $z_{L}$ and $z$ along the lidar beam path. On the assumption that the lidar is pointing vertically upward, the optical depth is given by

$$
\tau\left(z_{L}, z\right)=\int_{z_{L}}^{z} \beta\left(z^{\prime}\right) d z^{\prime}
$$


in which $\beta(z)$ is the atmospheric extinction coefficient per unit length. For a ground based lidar at sea level, $z_{L}=0$.

Because of the "matching" method of analysis described in Section A.1, it is clear that changes in the assumed extinction coefficient outside of the region of lidar analysis cannot affect the scattering ratio $R(z)$. For our purposes, it will therefore be convenient to break the optical depth $T\left(z_{L}, z\right)$ into two components,

$$
\tau\left(z_{L^{\prime}}, z_{b}\right)=\int_{z_{L}}^{z_{b}} \beta\left(z^{\prime}\right) d z^{\prime},
$$

and

$$
\tau\left(z_{b}, z\right)=\int_{z_{b}}^{z} \beta\left(z^{\prime}\right) d z^{\prime},
$$

so that

$$
\tau\left(z_{L}, z\right)=\tau\left(z_{L}, z_{b}\right)+\tau\left(z_{b}, z\right) \quad, \quad z_{L} \leq z_{b} \leq z
$$

where $z_{b}$ is the lower boundary of the region of lidar analysis. We thus have

$$
q^{2}(z)=Q^{2} q_{b}^{2}(z)
$$


in which

$$
Q^{2}=\exp \left[-2 \tau\left(z_{L}, z_{b}\right)\right]
$$

and

$$
q_{b}^{2}(z)=\exp \left[-2 T\left(z_{b}, z\right)\right] .
$$

In any given analysis using the "matching" method, since ${ }^{2}$ is independent of $z$, changes in $Q^{2}$ will be absorbed into the calibration constant $\mathrm{k}^{\prime}$ and thus are not of interest in the present discussion. We will therefore be concerned only with $q_{b}^{2}(z)--i . e$. , with the two-way transmission between the lower bound of the region of lidar analysis and some higher altitude $z$.

For the laser wavelengths of most stratospheric lidar systems, which are chosen to avoid the sharp absorption bands of water vapor and other gases, the extinction coefficient is the sum of three components,

$$
\beta(z)=\beta_{\mathbf{r}}(z)+\beta_{3}(z)+\beta_{p}(z),
$$

arising from Rayleigh scattering by molecules $\left(\beta_{r}\right)$, absorption by ozone $\left(\beta_{3}\right)$, and Mie scattering (including absorption) by particulate matter $\left(\beta_{p}\right)$. Analogously, the optical depth may be broken into three corresponding components:

$$
T_{i}\left(z_{b}, z\right)=\int_{z_{b}}^{z} \beta_{i}\left(z^{\prime}\right) d z^{\prime}, \quad i=r, 3, p
$$


In discussing the relative contributions of and possible variations in each of these components, we now assume for concreteness that $z_{b}-$ the lower bound of the region of lidar analysis--is at $10 \mathrm{~km}$ and that the upper bound is at $30 \mathrm{~km}$. We will also assume a wavelength $\lambda$ equal to $0.7 \mu \mathrm{m}$, or essentially equal to the ruby laser wavelength $(\lambda=0.6943 \mu \mathrm{m})$. With these assumptions, the Rayleigh and ozone optical depths over the region of lidar analysis may be readily obtained by using a standard atmosphere and a typical ozone density profile, as was done by Elterman (1968). His comprehensive tabulation shows that

$$
{ }_{\mathbf{r}}^{\mathrm{T}}(10 \mathrm{~km}, 30 \mathrm{~km})=0.010 \quad(\lambda=0.7 \mu \mathrm{m}),
$$

and

$$
\tau_{3}(10 \mathrm{~km}, 30 \mathrm{~km})=0.006 \quad(\lambda=0.7 \mu \mathrm{m}),
$$

where the U.S. Standard Atmosphere (1962) for molecular densities and a compilation of several observations for the ozone profile have been assumed. The corresponding two-way transmissions through the 10 to $30-\mathrm{km}$ region are thus

$$
\begin{aligned}
& q_{10, \mathbf{r}}^{2}(30)=e^{-0.020}=0.980 \quad \text { (molecular scattering) } \\
& q_{10,3}^{2}(30)=e^{-0.012}=0.988 \quad \text { (ozone absorption), }
\end{aligned}
$$

with transmissions to altitudes below $30 \mathrm{~km}$ lying even closer to unity. By varying the model optical depths [Eqs. (A.17) and (A.18)] one can easily show that deviations from the assumed standard molecular atmosphere of 50 percent or more and variations from the assumed ozone 
distribution of 160 percent or more are required to change the two-way Rayleigh and ozone transmissions by as much as 1 percent. Clearly, then, such variability may be ruled out as a source of significant error in the computed molecular lidar return and hence in the scattering ratio.

The third component of the stratospheric optical depth, $\tau_{p}\left(z_{b}, z\right)$, (the component due to particulate extinction) is, however, a possible source of significant error. For example, the 1968 Elterman compilation gives

$$
\tau_{p}(10 \mathrm{~km}, 30 \mathrm{~km})=0.027 \quad(\lambda=0.7 \mu \mathrm{m})
$$

for the particulate optical depth of the region that we are considering. This is 2.7 times as large as the Rayleigh optical depth and 4.5 times as large as the ozone optical depth. The resulting two-way transmission through the 10 to $30 \mathrm{~m}-\mathrm{km}$ region is

$$
\mathrm{q}_{10, \mathrm{p}}^{2}(30)=\mathrm{e}^{-0.054}=0.947 \text {, }
$$

and indicates that use of this particulate extinction model in the analysis of lidar returns will increase the scattering ratio at $30 \mathrm{~km}$ by $5.5 \%\left(\frac{1}{.947}-1\right)$ with respect to the scattering ratio at $10 \mathrm{~km}$. If, instead, the extinction in the 10 to $30-\mathrm{km}$ layer were assumed to arise entirely from Rayleigh scattering and ozone absorption (i.e., no particulate extinction), this 5.5 percent increase in the scattering ratio at $30 \mathrm{~km}$ would not occur. Such a change of 5.5 percent is certainly significant in relation to the accuracy of our current lidar measurements and the small peak scattering ratios $(R=1.10-1.20)$ currently being observed. Moreover, since the stratospheric particulate content is known to be highly variable [Elterman, 1968, pp. 8-19; 

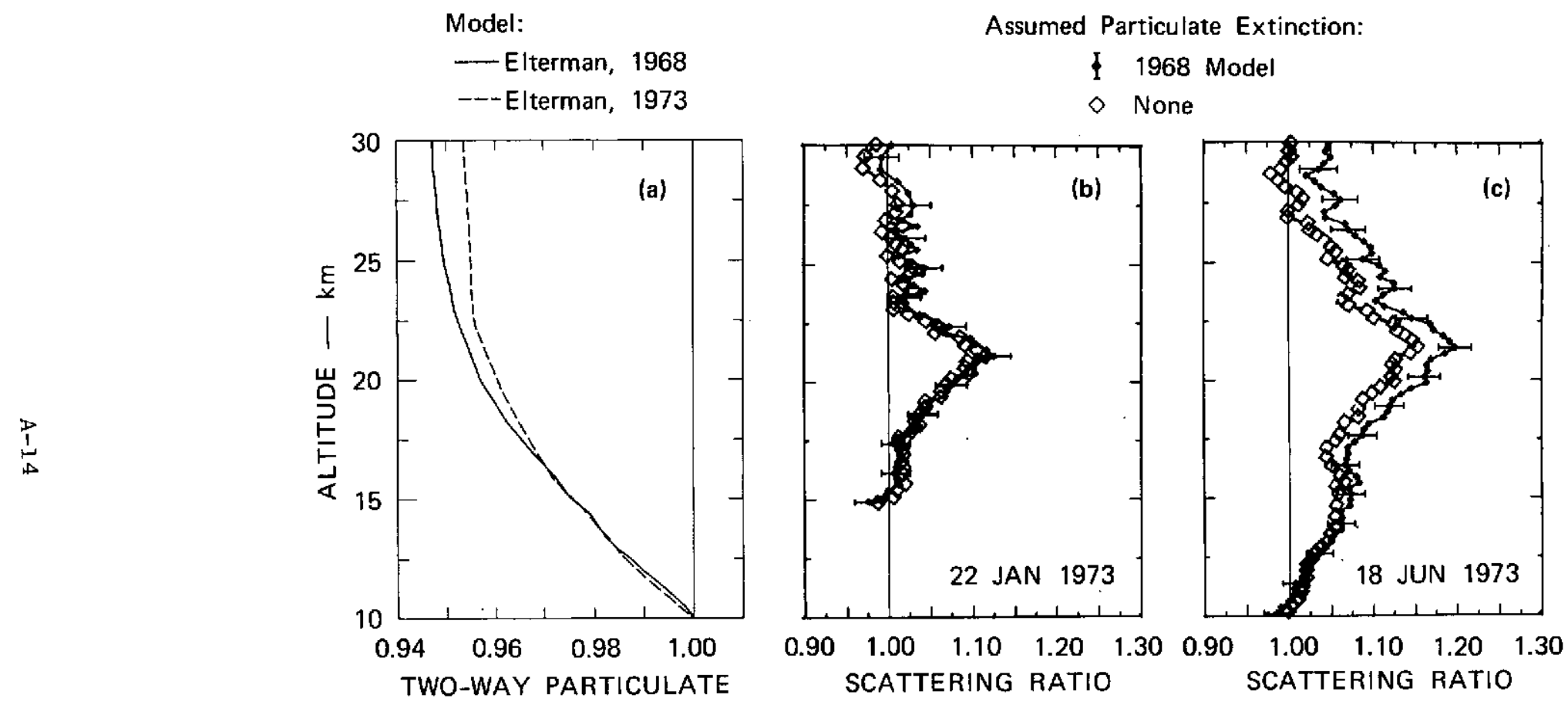

TRANSMISSION ABOVE $10 \mathrm{~km}$

FIGURE A2 EFFECT ON LIDAR SCATTERING RATIO OF ASSUMING MODEL [ELTERMAN, 1968; $\lambda=0.7 \mu$ ] PARTICULATE EXTINCTION OR NO PARTICULATE EXTINCTION IN COMPUTING MOLECULAR RETURN

(a) Two-way transmission above $10 \mathrm{~km}$ through model particulate extinction; (b), (c) Scattering ratios obtained using model particulate extinction and no particulate extinction. 
Fox, et al., 1973; and the text of this report], changes from the assumed stratospheric particulate optical depth by an order of magnitude or more should be considered possible. In fact, as discussed in the following section, a stratospheric particulate extinction profile that is much less than the 1968 Elterman model profile may provide a more accurate representation of present stratospheric aerosol conditions.

The effect of the above considerations is demonstrated by the use of two actual lidar observations in Figure A-2. Figure A-2(a) shows the profile of two-way particulate transmission, $\mathrm{q}_{10, p}^{2}(\mathrm{z})$, obtained assuming the 1968 Elterman particulate extinction model and a wavelength of $0.70 \mu \mathrm{m}$. As can be seen by inspection of Eqs. (A.2) and (A.3), this profile is divided into the measured lidar backscattering profile $S(z)$ in computing the scattering ratio $R(z)$. The resulting effect on the scattering ratio for our lidar observations made on 22 January 1973 and 18 June 1973 is shown in Figure $A-2(b, c)$. Scattering ratio profiles obtained from the same lidar data but assuming no particulate extinction in the 10 to $30-\mathrm{km}$ region are also shown for comparison.

The differences between the two profiles obtained on 22 January [Figure A-2(b)], where the lidar returns are analyzed only above $15 \mathrm{~km}$, are relatively small. This result could be predicted by inspection of Figure A-2(a) which shows that the 1968 Elterman particulate transmission over the 15 to $30-\mathrm{km}$ region varies by 3.1 percent or less. Since the 2.5 percent change in particulate transmission over the 10 to $15-\mathrm{km}$ region lies below the region of lidar analysis for this case, it is absorbed into the calibration constant in the matching procedure, independent of the extinction profile that is assumed. Similarly, a lidar profile analyzed only above $20 \mathrm{~km}$ would have its scattering ratios affected by only 1 percent in changing from a "no particulate" extinction to the 1968 Elterman model. This, in fact, was the reason for our early 
estimate of 1 percent for the one-standard-deviation uncertainty in computed scattering ratios caused by uncertain atmospheric extinction, as explained in the First Quarterly Report [Viezee et al., 1973a]. Half of the lidar observations presented in that report did not extend below $20 \mathrm{~km}$, and only one (19 January 1973) extended as low as $13 \mathrm{~km}$. The error bars shown in. Figure A-2 were also computed by using the 1 percent extinction-related uncertainty, so that they may be compared with the differences actually shown.

For the case of 18 June 1973, as shown in Figure A-2(c), the choice of an extinction profile becomes relatively more important. This is because the lidar return is analyzed over a large vertical range that extends down to $10 \mathrm{~km}$. In this region, the 1968 Elterman extinction is changing quite rapidly so that adopting that model rather than a "no particulate" extinction model increases the scattering ratio at $30 \mathrm{~km}$ by 5.5 percent with respect to the ratio at $10 \mathrm{~km}$. The "matching" method of analysis of course introduces a slight renormalization so that the mean of all ratios that are statistically equivalent to the minimum ratio remains equal to 1 . As can be seen, for lidar returns covering the range 10 to $30 \mathrm{~km}$, the assumption of a 1 percent error in the computed scattering ratio arising from extinction uncertainty is inadequate if both of the following two possibilities occur:

- The 1968 Elterman model is assumed

- It is considered likely that much smaller particulate extinction may, in fact, occur.

This question is addressed in more detail in the following section. 
4. Choice of an Appropriate Particulate Extinction Model

The particulate extinction model of Elterman (1968) has been used in all our previous analysis of lidar data and also in that of Melfi et al. (1973). On the other hand, Fox et al. (1973) have chosen to assume a model of no particulate extinction in their data analysis. Other researchers in this field may have chosen still other models. In view of the possible effects the choice of an extinction model may have (as illustrated above) on lidar-inferred particulate backscatter, it is important to evaluate the appropriateness of various particulate extinction models.

The model of Elterman (1968) is based on searchlight measurements made in 1964 and 1965. This period coincides with the early stratospheric lidar observations of Fiocco and Grams (1964) [see also Fiocco and Grams (1966), Grams (1966), and Grams and Fiocco (1967)] when peak scattering ratios in the neighborhood of 2.0 were observed. Since that time, with the passage of the Agung volcanic aerosol, commonly observed peak scattering ratios have been in the range 1.10 to 1.20 . The lidar data thus indicate a decrease in particulate backscatter in the stratosphere by as much as a factor of 10. Thus, the extinction values of the Elterman (1968) model are likely to be too large by a similar factor. More recent searchlight measurements by Elterman et al. (1973) made in 1970 show peak turbidity values that are 30 percent lower than the 1964-1965 values, but the 1970 peak is broader than the 1964-1965 peak, so that particulate transmission for the more recent measurements does not differ significantly from the Elterman (1968) transmission (both transmissions are plotted in Figure A.2(a) for comparison). Nevertheless, an earlier extinction model by Elterman (1964) showed stratospheric extinction coefficients an order of magnitude or more lower than those of the Elterman (1968) model. The 1970 searchlight measurements do not show a return to this pre-Agung condition although such a return is implied by the lidar and other measurements. 
The mutual consistency of the Elterman (1968) extinction model and the current lidar measurements may be further investigated by considering the particulate backscatter-to-extinction ratio implied by the two measurements. Following Waggoner (1971) and Waggoner et al. (1972), we define this ratio as:

$$
A \equiv 4 \pi \frac{f_{A}}{\beta_{p}} .
$$

We also require a definition of the turbidity $Y$, given by Elterman (1968) as:

$$
y \equiv \frac{\beta}{\beta_{r}},
$$

and we will use the fact that for Rayleigh scattering of unpolarized light,

$$
\mathrm{f}_{\mathrm{M}}=\frac{1.5}{4 \pi} \beta_{\mathrm{M}}
$$

These three equations may be combined with Eq. (A.1) to obtain the relation

$$
A=1.5 \frac{\mathrm{R}-1}{Y}
$$

that conveniently expresses the particulate backscatter-to-extinction ratio in terms of the fundamental quantities measured in a lidar and a searchlight experiment. 
The Elterman (1968) attenuation model shows a peak turbidity of

$$
y(\lambda=0.7 \mu \mathrm{m} ; z=19 \mathrm{~km})=4.67 .
$$

Generally, our observations, which are consistent with the recent ones of Melfi et al. (1963) and Fox et al. (1973), have shown peak scattering ratios of

$$
\mathrm{R}(\lambda=0.6943 \mu \mathrm{m} ; \mathrm{z} \approx 22 \mathrm{~km}) \approx 1.13 .
$$

Hence, using Eq. (A.24), we have

A (current 1idar $/ 1968$ El terman) $=0.04$.

This value may be compared with theoretical values computed under the assumption that the scatterers are nonabsorbing spheres with index of refraction $\mathrm{m}=1.5$ and a wide range of size distributions. The result of those computations is

$$
\mathrm{A}_{\mathrm{th}}=0.4-0.6 \cdot[\text { McCormick et al. (1968)] }
$$

In addition, experimental measurements on a wide range of troposphexic aerosols have been made, yielding

$$
A_{\exp }=\left\{\begin{array}{lll}
0.15 \pm 0.02 & {[\text { Waggoner et al. (1972)] }} & (\text { A.29) } \\
0.32 & {[\text { Reagan and Herman (1972)] }} & (\text { A.30) } \\
0.39 & {[\text { Davis (1971)] }} & \text { (A.31) } \\
0.3-0.5 & {[\text { Hamilton (1969)] }} & (\text { A.32) }
\end{array}\right.
$$


The generally smaller values of $A_{\text {exp }}$ as compared with $A_{\text {th }}$ probab1y result from the fact that real tropospheric aerosols are somewhat aspherical or weakly absorbing or both [see e.g., Holland and Gagne (1970), Harrison et al. (1972), and Grams et al. (1973)].

Comparison of the result in Eq. (A.27) with the theoretical result of Eq. (A.28) shows that, if the stratospheric aerosol particles are nonabsorbing spheres (e.g., sulfuric acid droplets) with index of refraction near $m=1.50$ and a reasonable size distribution, then the Elterman (1968) values for particulate extinction are too high by a factor of at least 10 [and the Elterman (1973) values too high by a factor of at least 7]. If, on the other hand, the stratospheric aerosol particles have a backscatterto-extinction ratio similar to that for tropospheric aerosols [cf Eqs. (A.29) through (A.32)], then the Elterman (1968) particulate extinction values are too high by a factor of 3.7 to 10 [and the Elterman (1973) values too high by a factor of 2.6 to 7 ]. In fact, the E1terman (1968) extinction values can be consistent with current lidar backscattering measurements only if any of the following three possibilities occur:

(1) The stratospheric particles are extremely aspherical, such as silica plates used by Holland and Gagne (1970).

(2) The scattering particles have an imaginary index of refraction $m_{1}$ of approximately 0.02 or larger (cf. Grams et al., 1973).

(3) Some combination of (1) and (2) applies, such as predominance of moderately aspherical particles (macrocrystals?) that have $m_{I} \approx 0.005$ or larger (cf. Harrison, et a1.(1972).

A recent study by Friend et al. (1973), which included laboratory experiments and a thorough survey of the literature, concluded that the composition of the stratospheric aerosol is predominantly ammonium sulfate and sulfuric acid. The sulfuric acid likely occurs in solution with water and--if the formation scheme proposed by Friend et al. (1973) is correct-would tend to be the dominant component shortly after volcanic exuptions, with ammonium sulfate dominating the "normal" stratospheric aerosol. 
Moreover, Friend (1966) and Mossop (1963, 1965) noted that electron microscope examinations of collected particles of ten showed evidence that the particles were associated with a liquid phase. Finally, another recent literature review and experimental program conducted by Neumann (1973) has shown that neither sulfuric acid (including sulfuric acidwater vapor solutions) nor ammonium sulfate is absorptive in the visible wavelength region used by stratospheric lidars. It thus appears quite doubtful that any of possibilities (1), (2), and (3) 1isted above actually occurs. However, crystals of ammonium sulfate with a nonzero imaginary refractive index too small to be measured by conventional techniques [possibility (3)] cannot yet be ruled out definitively.

Despite this final possibility, the bulk of the above evidence indicates that the stratospheric particulate extinction values of the El terman (1968) model are too large to be consistent with current lidar measurements showing peak scattering ratios in the range $R=1.10$ to 1.20. Moreover, these extinction values are probably high by a factor of 3 or more. It thus appears that use of this model in the reduction of lidar data with peak scattering ratios of 1 ess than $R=1.5$ is not appropriate, and in cases where the range of lidar analysis extends below about $18 \mathrm{~km}$ and covers a range of $8 \mathrm{~km}$ or more [cf Figure A.2(a)], significant exrors can be introduced by its use. At the present time, a "no particulate extinction" model as assumed by Fox et al. (1973) and used in Figure A.2(b), (c) is probably quite appropriate. A circumspect analysis procedure should, however, include a check that introduces a nonzero particulate extinction when scattering ratios of larger than about 1.3 are observed over a significant altitude region. Finally, these considerations should be taken into account in an error analysis when the probable contribution of extinction errors to computed scattering ratios and aerosol backscattering coeficients is being estimated. 


\section{REFERENCES}

Davis, P. A., 1971: Application of an airborne ruby lidar during a bomex program of cirrus observations. J. Appl. Meteor., 10, 1314-1323.

Dynatrend, 1973: Laramie comparative experiment, data report and preliminary report of conclusions. Edited by Dynatrend, Inc. (March 15, 1973 ).

E1terman, L., 1964: Atmospheric attenuation model, 1964, in the ultraviolet, visible, and infrared regions for altitudes to $50 \mathrm{~km}$. Report AFCRL-64-740, AFCRL, Bedford, Massachusetts.

Elterman, L., 1968: UV, visible and IR attenuation for altitudes to $50 \mathrm{~km}$, 1968. AFCRL-68-0153, Environmenta1 Research Papers, No. 285.

Elterman, L., R. B. Toolin, and J. D. Essex, 1973: Stratospheric aerosol measurements with implications for global climate. Applied Optics, 12, $330-337$.

Fernald, F. G., B. G. Schuster, and C. L. Frush, 1973: Comparison of lidar aerosol measurements and direct particulate sampling. Fifth Conference on Laser Radar studies of the Atmosphere, Wi11iamsburg, Virginia, 4-6 June, 1973, Conference Abstracts, pp. 31-33.

Fiocco, G., and G. Grams, 1964: Observations of the aerosol layer at $20 \mathrm{~km}$ by optical radar. J. Atmos. Sci., 21, 323-324.

Fiocco, G., and G. Grams, 1966: Observations of the upper atmosphere by optical radax in Alaska and Sweden during the summer 1964. Tellus, $18,34-38$.

Fox, R. J., G. W. Grams, B. G. Schuster, and J. A. Weinman, 1973 : Measurements of the stratospheric aerosol layer by airborne laser radar. To be published.

Friedlander, S. K, 1961: Theoretical considerations for the particle size spectrum of the stratospheric aerosol. J. Meteor. 18, 753-759. 
Friend, J. P., 1966: Properties of the stratospheric aerosol. Tellus, $18,465-473$.

Friend, J. P., R. Leifer, and M. Trichon, 1973: On the formation of stratospheric aerosols. J. Atmos. Sci. , 30, 465-479.

Grams, G., 1966: Optical radar observations of stratospheric aerosols. Thesis, Massachusetts Institute of Technology.

Grams, G., and G. Fiocco, 1967: Stratospheric aerosol layer during 1964 and 1965. J. Geophys. Res., 212, 3523-3542.

Grams, G., I. H. Blifford, Jr., D. A. Gillette, and P. B. Russell, 1973 : Complex index of refraction of airborne soil particles and implications for climatic change. Submitted to J. Atmos. Sci.

Hamilton, P. M., 1969: Lidar measurement of backscatter and attenuation of atmospheric aerosol. Atmos. Env., $\underline{3}, 221-223$.

Harrison, H. , J. Herbert, and A. P. Waggoner (1972): Mie-theory computations of lidar and nephelometric scattering parameters for power law aerosols, App1. Opt., 11, 2880-2885.

Hirono, M., M. Fujlwara, O. Uchino, and J. Itabe, 1972: Observations of aerosol layers in the upper atmosphere by laser radar. Report of Ionosphere and Space Research in Japan, 26, 237-244.

Holland, A. C., and G. Gagne, 1970: The scattering of polarized 1ight by polydisperse systems of irregular particles. Appl. Opt., $\underline{9}$, 1113-1121.

Junge, C. E., 1963: Air Chemistry and Radioactivity. New York, Academic Press, 382 pp.

Junge, C. E., C. W. Chagnon, and J. E. Manson, 1961: Stratospheric aerosols. J. Meteor., 18, 81-108.

Junge, C. E., and J. E: Manson, 1961: Stratospheric aerosol studies. J. Geophys. Res. 66, 2163-2182.

McCormick, M. P., J. D. Lawrence, Jr., and F. R. Crownfield, Jr., 1968 : Mie total and differential backscattering cross section at laser wavelengths for Junge aerosol models, Appl. Opt., 7, 2424-2425. 
Melfi, S. H., G. B. Northam, M. P. McCormick, J. M. Rosen, T. J. Pepin, and D. H. Hofman, 1973: Comparison of lidar and in-situ measurements of stratospheric aerosols. Fifth Conference on Laser Radar Studies of the Atmosphere, Williamsburg, Virginia, 4-6 June, 1973, Conference Abstracts, p. 35. (See al so Dynatrend, 1973, listed above.)

Mossop, S. E., 1963: Stratospheric particles at $20 \mathrm{~km}$. Nature, 199, 325-326.

Mossop, S. E., 1965: Stratospheric particles at $20 \mathrm{~km}$ a1titude. Geochim. Cosmock. Acta., 29, 824-827.

Neumann, J., 1973: Radiation absorption by droplets of sulfuric acid water solution and by ammonium sulfate particles. J.Atmos. Sci., 30, 95-100.

Regan, J. A., and B. M. Herman, 1972: Three optical methods for remotely measuring aerosol size distribution. Joint Conference on Sensing of Environmental Pollutants, Palo Alto, California, 8-10 November 1971, Paper No. 71-1057.

Schuster, B. G., F. G. Fernald, and C. L. Frush, 1973: G1 obal Reconnaissance of stratospheric aerosol by airborne lidar. Fifth Conference on Laser Radar Studies of the Atmosphere, Williamsburg, Virginia, 4-6 June 1973, Conference Abstracts, p. 34.

U.S. Standard Atmosphere, 1962, for sale by Superintendent of Documents, U.S. Government Printing Office, Washington, D.C. 20402.

U.S. Standard Atmosphere Supplements, 1966; for sale by Superintendent of Documents, U.S. Government Printing Office, Washington, D.C. 20402.

Viezee, W., R. D. Hake, and P. B. Russell, 1973a: Lidar measurements of stratospheric constituents. First Quarterly Report, Contract NAS2-7261, Stanford Research Institute (March 1973).

Viezee, W., R. D. Hake, and P. B. Russel1, 1973b: Lidar measurements of the variability of stratospheric particulates. Second Quarterly Report, Contract NAS2-7261, Stanford Research Institute (June 1973).

Waggoner, A. P., 1971: Measurement of backscatter and total scatter of the atmospheric aerosol at $694 \mathrm{~nm}$. Thesis, University of Washington.

Waggoner, A. P., N. C. Ah1quist, and R. J. Charlson, 1972: Measurement of the aerosol total scatter-backscatter ratio, Appl. Opt., 11, 2886-2889. 